\title{
Savings From Energy Efficient Windows: Current and Future Savings From New Fenestration Technologies in the Residential Market
}

\author{
Karl Frost, Dariush Arasteh, and Joe Eto \\ Energy and Environment Division \\ Lawrence Berkeley Laboratory \\ University of California \\ Berkeley, CA 94720
}

April 1993 Technologies, Building Systems and Materials Division of the U.S. Department of Energy under Contract No. DE-AC03-76SF00098. 


\title{
Savings From Energy Efficient Windows: Current and Future Savings from New Fenestration Technologies in the Residential Market
}

\author{
Karl Frost, Dariush Arasteh, and Joe Eto \\ Energy and Environment Division \\ Lawrence Berkeley Laboratory \\ University of California \\ Berkeley, CA 94720
}

\begin{abstract}
Heating and cooling energy lost through windows in the residential sector (estimated at two-thirds of the energy lost through windows in all sectors) currently accounts for 3 percent (or 2.8 quads) of total US energy use, costing over $\$ 26$ billion annually in energy bills. Installation of energy-efficient windows is acting to reduce the amount of energy lost per unit window area. Installation of more energy efficient windows since 1970 has resulted in an annual savings of approximately 0.6 quads. If all windows utilized existing cost effective energy conserving technologies, then residential window energy losses would amount to less than 0.8 quads, directly saving $\$ 18$ billion per year in avoided energy costs. The nationwide installation of windows that are now being developed could actually turn this energy loss into a net energy gain. Considering only natural replacement of windows and new construction, appropriate fenestration policies could help realize this potential by reducing annual residential window energy losses to 2.2 quads by the year 2012 , despite a growing housing stock.
\end{abstract}

\section{Introduction}

Windows are responsible for a large portion of the energy used in buildings. Although windows do not consume electricity or natural gas directly, the heat energy lost or gained through windows directly affects the amount of energy required to maintain comfortable indoor conditions. Significant advances in fenestration technology have been made to the point where windows can actually be net sources of useful heat to a building. As a result of these advances, a wide array of new, energy-efficient windows are entering or are soon to enter the market.

These technologies have yet to realize their full potential energy savings. This potential lies both in the construction and design of new buildings and in the retrofitting and remodeling of existing ones. Public and private sector interventions into the fenestration market could cost effectively accelerate the adoption of these energy saving fenestration technologies. We therefore need an understanding of the magnitude of this resource and how to best utilize it.

However, the installation of windows, like most energy efficiency opportunities, is inherently diffuse, decentralized, and diverse. The energy lost through windows is the cumulative loss from millions of windows installed in a variety of building structures, operated in a variety of ways, and located across the country. Understanding the potential for window energy efficiency improvements on a regional or national basis, consequently, requires an appreciation of these unique characteristics of the resource. 
This paper describes an analytic tool developed to estimate window energy use and the potential for advanced window technologies to save energy. It combines highly disaggregated data on existing and projected window stocks, building thermal integrities, and heating, ventilation and air conditioning (HVAC) equipment efficiencies on a consistent basis to produce regional estimates of window energy losses for a variety of window technologies.

We use the tool to estimate the contribution of energy losses from residential windows to total US energy use. We also estimate the annual savings which are resulting from the adoption of more energy efficient windows since 1970. Finally, we speculate on the potential energy savings that could result from greater adoption of currently available advanced window technologies in the residential sector. The commercial sector, although having one third of the national window stock, has different energy needs, requiring a different physical model and is therefore not modeled in this paper.

The tool which we have developed addresses a middle ground between forecasting models and technical potential studies. We rely on the rich data structure of end use forecasting models to assemble a consistent framework for assessing the impacts of window energy loss on the basis of location, building type, fuel, and HVAC equipment type. We go beyond traditional end use forecasting models by further characterizing the energy use consequences of various fenestration technologies on residential heating and cooling loads with the use of a building energy simulation model. This detailed, technology-based description is traditionally considered by technical potential studies. However, whereas technical potential studies often suppress details of market dynamics, we rely on forecasting data for the turnover of housing stock and technology diffusion to estimate an explicit rate of adoption for window technologies.

We describe this tool and its application in the five sections following this introduction.

\section{Window Technologies and Energy Consumption}

The last decade has seen many advances in our understanding of energy transfers through windows; this understanding has been reflected in the introduction of new energy conserving fenestration products to the market [Selkowitz 1985, Warner 1990]. These products are aimed at reducing heat losses (or gains) through windows by controlling (1) thermal conductance resulting from temperature differences between inside and outside air, (2) solar gains from direct sunlight through windows, and (3) infiltration of air from outside the building.

Efforts to reduce thermal losses through windows have focused mainly on reducing the heat transferred directly through a window's materials: the thermal conductance. A window's thermal conductance is captured in the measurement of its $U$-value, the amount of heat transferred via thermal conductance through the window per unit of temperature difference between the inside and outside. Many technologies have been developed to reduce a window's Uvalue. A prime example is insulating glass, which uses two or more sheets of glass separated by air or gas filled gaps in place of the traditional single pane of glass; insulating glass can more than cut in half the thermal conductivity of a glazing system (see Figure A) [Arasteh, Selkowitz, and Hartmann 1986]. This cost-effective use of multiple glazing layers to reduce thermal losses has become the most common glazing system in the national window market and is in many states required to meet new construction standards [AAMA 1979 - 1991, NCSBCS 1991].

Other more recently developed technologies to reduce thermal conductivity are steadily increasing in market shares. Low-emisivity (low-e) coatings, which virtually eliminate internal 
radiative heat transfer by absorbing infrared radiation [Arasteh, Selkowitz, and Hartmann 1986], have in the past decade moved from the research laboratory to occupy a third of the residential window market. Also, low-conductivity gases, like argon, are now being used to replace air in a sealed insulating glass unit, further reducing heat transfer through windows [Reilly, Arasteh, and Rubin 1989].

As glazing systems have become less conductive, it has become apparent that the window frame is also a source of heat loss. Of the frame types in general use, metal frames, made out of aluminum or steel, have been shown to have the highest conductivity. To mitigate the conductivity of aluminum frames, thermal breaks -- non-metal structural elements in metal extrusions which significantly reduce heat transfer through the frame -- are often used. Vinyl frames, which have a thermal conductivity as low as or lower than that of wood, have also been developed for mass production and can often be purchased for less than the cost of an aluminum frame with thermal breaks. Vinyl frames have grown in the past decade from occupying only a small fraction of the market to representing a quarter of residential window sales. Today's low-e, argon filled window in a vinyl frame has a resistance to heat transfer about four times that of a single-glazed aluminum framed product manufactured in the 1970's [ASHRAE 1991].

Superwindows, comprehensively utilizing all of these technologies, can cut these heat losses in half while still allowing useful solar heat gains to enter a space, thereby turning the windows from sources of energy loss into sources of energy gain [Arasteh 1989]. Table A gives a comparison of the U-values of different available technologies [Window 4.0 1992].

In cooling dominated climates, thermal conductance is not the primary source of energy loss. Solar heat gains through windows, a boon during the winter heating season, can significantly increase air conditioning loads during the summer cooling season (see Figure A). A number of technologies counteract the effects of solar gains. One of the simplest and oldest is the external shade. A shade outside the house, such as an awning or tree, blocks direct solar radiation and reradiates the heat outside of the dwelling (an internal shade would reradiate primarily inside the house, reducing glare but still contributing somewhat to unwanted heat gain) [Selkowitz 1985]. Reflective and tinted coatings on windows have a similar effect but for aesthetic reasons aren't used ofton in residential settings; these technologies reduce the cooling load, but block desirable light. In response to the negative aspects of tinted coatings, spectrally selective coatings have been developed. These coatings, which are just becoming widely available, block solar radiation outside of the visible spectrum, preventing most unwanted solar gains while leaving the perceived interior daylighting from visible light relatively unchanged [Schuman 1992]. Thus, one can have a window which is visually indistinguishable from a clear glass window of twenty years ago, but which results in one half of the solar heat gains. Still in the research stage is the technology of electrochromic glazings, which have an electronically switchable tint, like the liquid crystal technology of the electronic watch or calculator. Electrochromic glazing can be adjusted to reduce daylight and solar heating when the sun is at its peak and to allow in more daylight when the glare is not as great [Selkowitz 1986]. Table A also compares the shading coefficient - the fraction of solar heat gain in comparison to that from a single glazed window -- of different glazing technologies [Window 4.0 1992].

In addition to thermal conductance and solar gain, a third main avenue of heat transfer through windows is infiltration, unintended ventilation through a closed window (see Figure A). If an installed window has too many or too large air gaps, then conditioned air from inside the building will escape, and unconditioned air will enter, resulting in heating or cooling energy 
losses. This problem is reduced by tighter design of windows and better installation and caulking of joints [Wiedt and Wiedt 1980]. Acknowledging the effect of infiltration on energy consumption, industry standards have been getting tighter. In the early $1980 \mathrm{~s}$, the industry standard for infiltration was 0.5 cubic feet per minute per linear foot of crack under 25 mile per hour wind conditions; the standard is now $0.37 \mathrm{cfm}$ per linear foot under the same conditions. Due to problems arising during installation or wear and tear on the window, the actual infiltration of installed windows in the housing stock is often found, however, to be up to 1 to $1.5 \mathrm{~cm}$ per linear foot. A well-designed and well-installed window, on the other hand, can allow less than 0.1 cfm per linear foot.

\section{Recent Trends in the Fenestration Market}

An important measure of a technology's impact is its performance in the market. By this measure, energy-efficient windows have had a strong impact during the past two decades. The sales of energy-efficient window technologies have been climbing rapidly since 1970, though the sales of some have been leveling off during the past few years.

Figures $\mathrm{B}$ and $\mathrm{C}$ and Table $\mathrm{B}$ present national sales data on windows in the residential market by frame and glazing technology since 1974, gathered from a variety of sources [AAMA 1979 - 1991, AAMA 1988b, NWWDA 1990, Azon 1992, Cunningham 91, Barbee 1988, Energy Design Update 1989 and 1992, Koomey et. al. 1991]. The quality and accuracy of the different sources vary. For example, although the NWWDA and AAMA data are within a few percent of each other for regional new construction figures, NWWDA cites a much larger remodeling market - in a few regions up to 50 percent larger than AAMA identifies. Despite such problems with the data, some features can fairly reliably be distinguished. A main feature that stands out from the data is the decline in window sales since 1987. This decline coincides with the fall of the new housing market after the overbuilding of the early eighties [Dodge/Sweet 1992, AAMA 1991]. Though the residential market did not overextend itself as much as the commercial market, it will still take time before the dip in sales levels out especially given the current state of the economy. The rise in remodeling and retrofitting expenditures, however, has saved the residential market from a more serious collapse, illustrated in Figure $D$.

The data in Figures B and C and Table B also indicate that the market has been moving toward the sale of lower U-value windows. Wood frames are now half of the market, while vinyl frames have been climbing rapidly and are now at almost 25 percent market penetration. Aluminum frames have been declining in use, but when one looks at finer details of aluminum frame sales, one sees that the use of aluminum frames without thermal breaks is plummeting, while aluminum frames with thermal breaks are experiencing only a minor decline in use. Further, data from the last decade suggest that vinyl frames are displacing aluminum frames in a significant percentage of their market niche. Given the steepness of the changes in both aluminumi and vinyl frame markets, this pattern of market evolution can be expected to continue for some ime before leveling off. It is also apparent from Figure $D$ that the penetration of energy-efficient frames is greater in the remodeling market although it is unclear if this effect is caused by a greater concern for energy savings on the part of the home owner as opposed to the builder, the geographic distribution of remodeling vs. new construction, the effects of targeted advertising, or some other factor. 
With regard to glazing type, it is clear that insulating glass units are taking over the market. In 1970 they represented only 14 percent of the market, but today they are almost 90 percent of the glazing market and still climbing. Among insulating glass units, there has also been a great deal of market movement during the last ten years toward lower U-value units. In 1982, the most insulating window widely available on the market was a simple double glazed system; today, however, one third of insulating glass units have both argon fill and low-e coatings. Also, there is a fledgling market developing for superwindows with three or more glazing layers and multiple low-e coatings.

Figure $\mathrm{E}$ traces the mean $\mathrm{U}-\mathrm{Value}$ of windows sold during the past twenty years. The move toward a lower U-Value implies significant savings in home heating costs, as will be shown.

Figure $\mathrm{F}$ shows that storm window sales have been declining since 1986. Compared to the window market as a whole, the market for storm windows has been in a state of decline since 1978 , when the sales of storm windows (in terms of number of units sold) were almost twice that of prime windows. This decline is possibly the result of the use of double glazing as a substitute for storm windows and of the saturation of the retrofit market.

The market has also moved towards glazing systems that have lower shading coefficients. In most climates, where heating concerns dominate, this move is perhaps just a side effect of moving toward a lower U-value. However, this move toward lower shading coefficients will also have significant benefits in cooling dominated climates, especially as new technologies hit the market. Rich Brown illustrated this point by calculating the effect of using spectrally selective glazings in California [Brown, Arasteh, and Eto 1992]. If 90 percent of windows were sold with spectrally selective coatings in California by the year 2010, then by that time, approximately 1 Tbtu would be saved annually in cooling costs -- the equivalent of 200,000 barrels of oil per year.

Of course, the relevance of different energy conserving technologies depends on where they are sold. Unfortunately, not many regional data are available. Some regional data on frame type, however, are available from NWWDA; these are illustrated in Figure G. Data are available from NAHB on average glazing layers installed in 1987 in new, single family detached homes, shown in Figure $\mathrm{H}$ (Though these figures cannot be readily extrapolated to window sales as a whole, being representative of only a fraction of the new housing market, they can give an indication of where multiple glazing systems and single glazing systems are being sold.). As would be expected, lower U-value technologies are concentrated more in the north, where heating is more of an expense, while aluminum frames are largely concentrated in Florida and California, where there is both a large new housing market (which has a much higher use of aluminum frames than does the remodeling market) and a warmer climate.

Any extrapolation from this set of data to future sales must be tentative, at best, for a number of variables in the window market picture are still unresolved. A straight line extrapolation from the current data may be good as a first guess at where window sales will be going, but possible building codes, standards and regulations under discussion could have drastic effects on the window market. In addition, the new national energy strategy for window technologies is expected to have significant effects on the market, both through direct effect on consumer awareness and indirect facilitation of standards and regulations. In order to understand the possible or probable effects of these different scenarios, one needs a methodology for estimating future sales and building activities in different market and policy environments and implications of new window installation for local and national energy consumption. 


\section{Methodology}

Predicting the energy implications of different fenestration policy and technology scenarios involves three points of analysis: demographics, physical modeling, and market analysis/social modeling. Demographic information is necessary to determine "what is out there" and to identify current trends. A detailed physical model is necessary to determine accurately the energy implications of different fenestration technologies in the very different climate zones of the United States. Finally, a model that can capture the effects of market dynamics and policy decisions is necessary for the analysis to have practical importance.

\section{Demographics}

Demographic information is needed on the housing stock, sales of window technologies, and other social, legal, and climate factors that influence the choice of fenestration technology. Much of this information is available at some level of aggregation, ranging from national to state or even finer levels. Demographic searches must cover several different ranges of variables: residential window stock; residential window sales (flow); the heating, ventilation and cooling equipment (HVAC) stock and sales; climate types; and social, market and policy factors affecting window installation.

Detailed information by region on the window stock, covering the different glazing and frame technologies, is necessary for an estimate of energy losses that is more precise than a simple order of magnitude calculation. Total square feet of each window type must therefore be derived for each region from housing surveys, construction surveys, and past regional sales data. These data allow the accurate calculation of residential windows' contribution to our national energy consumption.

In order to estimate how this energy consumption will change, however, one needs not just the window stock, but the additions to and removals from the stock through new construction, remodeling, and housing demolition. Unless draconian measures are employed to force a change in everyone's installed windows, windows purchased for new construction and remodeling will determine significant portions of our heating and cooling expenditures for several decades into the future. Given the 35-year to 45 -year life span of the average home window, a window, once purchased and installed, is a commitment to a certain level of energy consumption for several decades. For forecasting purposes then, the estimates of past window sales gathered from industry and construction surveys and from trade journal reports will be used as the basis of projections, while the National Energy Strategy estimates for housing growth and the EIA Annual Energy Outlook projections of energy prices will be used to evaluate impacts (NES 1990, EIA 1993).

This window stock and flow must also be associated with an HVAC stock and flow, so thermal loss and gain numbers can be converted into actual units of fuel consumed (gas, electricity, oil, or other fuels). Information on HVAC systems is available from housing surveys and past LBL housing modeling efforts.

Once these data have been gathered and organized by region, regional energy losses and savings through windows can be estimated, and plausible projections of energy-efficient window technology implementation can be calculated using appropriate physical and market models. 


\section{Physical Model}

The Windows and Daylighting Group at LBL has done extensive research on the thermal conductivity of window systems, ranging from direct experimentation and observation with IR cameras in simulated climate conditions to computer simulations of window technologies. Two of these computer simulations serve as the basis of our physical model: WINDOW 4.0 and RESFEN [Windows and Daylighting Group, Sullivan]. WINDOW 4.0 is a publicly available software tool for the PC, which takes window specifications and accurately calculates window Uvalues and shading coefficients. RESFEN takes the given U-value, shading coefficient, infiltration rate, and orientation for a winduw and calculates the heating and cooling losses through the window, given its location in one of ten climate sites, based on a regression model of DOE-2 building simulation model runs [DOE-2].

These models have been validated empirically in a variety of contexts, and they capture complex physical dynamics not captured by more simplistic calculations. For example, using the standard heating/cooling degree day calculation, one would miss the "whole house" dynamics captured by the DOE-2 building simulation; these dynamics result in a small, or even inverse relationship between $\mathrm{U}-\mathrm{Value}$ and cooling expenses, depending on the climate zone. Neglect of these dynamics can thus lead to an overestimate of the importance of $U$-Value to cooling costs [ASHRAE 1992, DOE2].

Because of the large variations in climate and heating and cooling needs among the regions of the US, the window stock must be broken down into regions reasonably characterizeable by a given average weather pattern. The climate types are taken from the ten climate sites built into RESFEN. With future RESFEN upgrades for more climate sites and higher resolution of the regional window stock and sales data, the physical model will be the most accurate component of the energy consumption forecasting calculation.

\section{Market Penetration Model}

There is no consensus on any one best market model, which is reasonable given the complexity of the market and the general lack of information it. What we need is a range of different models to choose from, depending on what effect we are attempting to analyze and what sort of data we have available. For example, in a fairly static market for apples and oranges, a price based econometric model may be just the tool to suggest how very small price differences among apples and oranges may affect overall sales. However, in attempting to determine how effective a given utility rebate program will be for insulation or double glazed windows, an econometric model may be inadequate because its linear approximations cannot effectively analyze large changes in the market, and it fails to account for dynamics that have often proven in case studies to be more important in determining sales than consumer price; a rebate program's perceived legitimacy and its advertising technique are but two examples of factors that have proven to be as important, if not more, than differences in the size of the rebate and thus price [Nadel 1991, Stern 1986, Lutzenhiser and Hackett 1991].

A market-diffusion-based model was selected as the basis of our market model so that data requirements can be more easily met and actual use and methodology will be transparent (see Appendix A). In the diffusion model of market dynamics, it is postulated that for a given product, 
there is a certain "market potential" for sales, conceptually similar to the econometric notion of a market equilibrium level of sales. This market potential is determined by a complex combination of factors, including price dynamics, consumer needs and attitudes, and regulations that affect both availability of technologies and their prices as seen by the consumer. The market potential is not immediately realized, however, as a simple econometric analysis postulates. In theory, a product is introduced to the market, and certain individuals, the "market pioneers", are drawn to the technology. Next, other consumers are convinced to adopt the new technology after observing it in use. This process continues until a stable level of sales -- the "market potential" -is reached. The time pattern of sales follows a logistic curve with different technology types having different diffusion coefficients and different market potentials, given by

$$
S=P\left[1-(1+\beta T) e^{-\beta T}\right]
$$

where $S$ is sales, $P$ is the market potential, and $\beta$ is the logistic curve coefficient determining the "speed" with which sales approach the market potential, $P$. This diffusion curve is illustrated in Figure I.

Just as the econometric model has problems, so does the market diffusion model. Determining the market potential and the coefficients of the logistic curve is the first problem encountered; limited data on sales along with a playing field of dynamic regulations and technological innovations, makes the calculation of these parameters difficult at best. Estimating a market potential can be accomplished, however, through a combination of extrapolation from sales data and a region-by-region cost benefit analysis, given a regional distribution of homes, windows, incomes, climate, regulations, incentives, and lifestyles. Because of uncertainties in these numbers, the nature of their interrelations, and the cost of the technology at different levels of production, this estimate is by nature a rough one. The coefficients of the logistic diffusion curve can be taken from historical data on window technologies. Existing data on insulating glass, low-e coatings, argon fills, vinyl frames, and thermal breaks can indicate typical speeds of adoption for new fenestration technologies, as is illustrated in Figure $\mathrm{J}$.

The primary problem, however, is the modeling of regulations and incentives. The tracitional diffusion model approximates an effect that is the aggregate of many individual decisions; however, it does not model, by itself, the dynamics of individual decision making. Therefore, it does not explicitly have a means of modeling the effects of regulations and incentives. The model used will therefore be a modified diffusion model, taking into account the discrete choices that can be made with regulations and incentives. Regulations can be modeled as discrete changes in market sales; what would, before the discrete change, be sales in "banned" technologies are redistributed according to newly calculated market potentials. Incentive programs are more difficult to model. On the one hand, they change the market potential by changing the prices. On the other hand, they may more strongly increase awareness of a technology and legitimize the technology, so they should be modeled as increases in the diffusion coefficients, rather than as increases in the market potential. Incentive programs are therefore modeled as a combination of change in diffusion coefficient, change in market potential, and (in the case of intensive "promotional blitzes") as discrete change in sales, depending on the program in comparison to the growing body of other programs that have been tried and studied in the energy conservation field.

The market modeling tool, as described in this section, is a database of regional window stock and window market factors and a formalized framework for applying historical data and 
case study information; as such, it can serve as a strategic planning tool for regulators, researchers, and utilities.

\section{Model Implementation}

Figure $\mathrm{K}$ is a flow chart of the actual model. It is broken down into the three stages: window stock characterization, energy consumption calculation, and market forecasting. Associated with each block of the model are the outputs from the model and a group of data sources, used to derive variable values.

\section{Characterization of the Window Stock and HVAC Stock}

Our demographic search generated the data in Figures $L, M$, and $N$. These figures present estimates of various parameters of the window stock in the US in square feet by region. These results were derived from a number of sources, primarily 1987 RECS, 1991 Statistical Abstract, NPPC, and the past sales data [RECS 1987, Statistical Abstract 1991, NPPC 1991; see Trends section for sales references]. A number of problems arose, however, in attempting to get an accurate picture of the window stock aggregated to the desired levels. These problems included: data being too aggregated, data being unavailable in the desired form (such as being only available in window units, instead of window area), data being only available for certain regions, and accumulation of successive estimation errors. These problems were addressed by reasonable assumptions and extrapolations as detailed in Appendix B.

Outstanding in the data on glazing stock is the large, remaining presence of single-glazed windows. Despite the strong current market penetration of insulating frames, the thirty-year to fifty-year life span of the average residential window implies a slow turnover of the glazing stock. Also, a larger aluminum frame stock is evident in the western states where the construction market has been more characterized by new construction -- in response to migration west -- as opposed to remodeling, which has characterized the market in the east and Midwest. Further, as is to be expected, the less thermally conductive glazing systems represent a higher percentage of the stock in colder climates where space conditioning needs are more of an issue.

Tables $\mathrm{C}$ and D present data on HVAC stock and representative efficiencies. The information on the stock was taken from RECS while the data on representative efficiencies of the stock was taken from LBL-REM [RECS 1987, LBL-REM 19:92].

\section{Calculating Heating and Cooling Losses by Fuel type}

Given the window stock depicted in Figures L, M, and N, the physical model was applied to derive energy losses by region. The RESFEN model of window heating and cooling losses was used to calculate these thermal losses through windows. Assuming that the 1987 RECS HVAC stock gives representative figures for 1991 heating fuels used and air conditioner installation, we can apply the RESFEN model to the window stock to generate the figures in Table E for energy consumption by fuel type. We assume that each window type has the same distribution with respect to the different HVAC types; however, in reality, more energy-efficient windows may be associated with the more energy-efficient HVAC systems, so these figures represent a slight 
underestimation of energy consumption, but the error from this assumption is assumed to be small compared to other errors.

As is illustrated in Table $\mathrm{E}$ and Figure $\mathrm{O}$, windows in the residential sector were determined to be responsible for about 2.8 quads, or about three and a half percent of our national energy consumption. Given current energy prices, this 2.8 quads directly costs $\$ 26$ billion in heating and cooling bills each year, not to mention the environmental costs of increased energy consumption and additional reliance on foreign sources of energy to which this 2.8 quad annual drain contributes [EIA, State Energy Price and Expenditure Report 1990].

This energy loss can be broken down further by function. Most of this energy, 2.4 quads, goes toward heating losses, while 0.4 quads goes toward cooling. However, although only 15 percent of these energy losses are due to cooling losses, cooling losses are responsible for 25 percent of the costs of energy losses because of the higher price of electricity. Approximately 70 percent of the window energy losses are to be found in the northern half of the US.

\section{Calculating Future Changes in the Window Stock and the Resultant Energy Savings or Losses}

As a precursor to implementing the more complicated market diffusion model, estimates of possible energy savings from new window technologies and new fenestration codes can be made, based on sales information and projections of policy targets. Detailed estimates of this kind have been made for California and the North Central Federal Region by Brown, Arasteh, and Eto; estimates for the whole nation are given in the next section.

\section{Demonstration of the Model}

Brown, Arasteh, and Eto used an earlier version of the model to analyze the implications of different fenestration policies in two regions: the Central Valley of California and the North Central Federal Region (MT, UT, CO, WY, ND, SD) [Brown et al. 1992]. They compared the energy savings from two different policy scenarios, one encouraging the implementation of advanced energy-efficient fenestration systems, and the other a "hands off" approach without market intervention. The two technologies examined were superwindows for the North Central region and a selective glazing system in California's expanding Central Valley Region. The encouragement of superwindows in the North Central Region led to a calculated savings of 1.6 TBtu/yr over the "no policy" scenario by the year 2005. The encouragement of selective glazing in California led, by the year 2005, to a savings of $6.1 \mathrm{TBtu} / \mathrm{yr}$ over the "no policy" scenario. (See Appendix C.)

\section{Energy Savings in the US Window Stock}

Applying the model to a more broad scope, we answered two questions about the impacts of energy efficient fenestration technologies on the US housing stock:

1. What energy savings have resulted from advances in the sales and installation of energy conserving fenestration systems since 1970?

and 


\section{What are the potential energy savings attainable from the use of advanced energy efficient windows?}

\section{Achieved Savings}

In order to answer the first question, we compared the energy losses due to the existing fenestration stock to a hypothetical stock that would have resulted in 1991 without either the increasing sales of double glazing since 1970 or the introduction of more advanced glazing systems. We assumed that market shares of different fenestration technologies were frozen at 1970 levels, but that the sales volumes were otherwise unaffected. Some of the implications of this freeze are that vinyl frames, thermal breaks in aluminum frames, low-e coatings, and argon fills would not have been sold (or installed) and that double glazing sales would have been frozen at the level of 14 percent of the market. In contrast, the current market has almost 90 percent market penetration of double-glazed windows. It was assumed that the vinyl frames would have been sold as aluminum frames and that the aluminum frames with thermal breaks would have been sold without thermal breaks.

Using the same HVAC stock and physical calculation as that used in the estimate of current energy losses, the results of Table $F$ were generated. The total annual US energy losses through windows would have been 3.4 quads without the advances in energy-efficient window installation since 1970 - a difference of 0.6 quads. Given current energy prices, this is a direct realized savings of $\$ 5$ billion per year in avoided heating and cooling bills. The savings can be broken down into 0.77 quads heating and 0.01 quads of cooling. The vast majority of these savings are apparently to be found in heating savings.

In perspective, our 1991 energy consumption as a nation in all sectors was 81 quads. Thus, the implemented changes in window design since 1970 are already paying off with energy savings in the residential sector which are equivalent to half a percent of our national energy consumption.

\section{Potential Savings}

There are a number of ways to describe the potential energy savings from energy-efficient windows. One could calculate the energy losses would if all residential windows were retrofit with the best windows available or possible, thus avoiding questions about the change in the size and location of the window stock and the rate at which it can be changed. This method is useful for getting a picture of the performance of existing windows versus the performance of optimal windows. One could also project the stock to some future point in time under a range of window sales scenarios and calculate the energy losses of these stocks. These projections are useful for getting a sense of how fast change can happen and to what levels of energy consumption we are now committed. We describe the potential for energy savings with both methods.

To calculate the heating and cooling losses from a US window stock composed of the best available windows, we assumed that the HVAC stock and the size of the window stock are again identical to the status quo. The northern climates (Northwest, Mountain North, West North Central, East North Central, New England, and Mid Atlantic), however, will have only today's best available superwindows installed, and the cooling dominated southern climates (California, Mountain South, West South Central, East South Central, South Atlantic, and Florida) will have 
only selective glazing systems with therınally resistant frames installed (see Table A for U-Value and Shading Coefficient. The infiltration rate was assumed to be $0.1 \mathrm{cfm} /$ linear $\mathrm{ft}$ ). Table $\mathrm{G}$ shows the energy consumption results of this installation pattern.

With complete implementation of existing energy-efficient window technologies, windows would lose only 0.80 quads per year of space conditioning energy, saving \$18 billion in heating and couling bills. Two thirds of the heating and cooling losses through windows could then be saved through the implementation of the two technologies mentioned above. This 0.80 quads can be broken down to 0.62 quads of heating and 0.17 quads of cooling - a 1.8 quad savings in heating energy and a 0.19 quad savings in cooling. Cooling energy use could be cut in half, and the heating energy lost through windows could be cut to one quarter of current levels. The energy savings from the installation of these technologies in residences alone would result in annual energy savings that are isuivalent to two percent of our national energy consumption or 12 percent of our net energy imports.

This 1.41 quad savings is not, however, the limit to attainable savings. Window technologies still being researched have the possibility of being net energy gainers for the house, where winter heat gains from the windows more than compensate for both the winter heat and summer cooling losses through the windows. Complete installation of this type of window in the housing stock, modeled as a $0.1 \mathrm{U}$-Value electrochromic window (except in Florida, where a UValue of 1.0 was used) results in a net energy gain for the US of 1 quad per year (see Table $\mathrm{H}$ ). A $\$ 26$ billion dollar a year drain thus has the eventual potential of turning into a $\$ 5$ billion dollar a year resource. Looking more closely at the table reveals that all locations except Florida have a net energy gain. As window: can only contribute heating energy and Florida is cooling dominated, there isn't enough heating savings to counterbalance cooling savings.

To project window energy losses in the year 2012, we assumed that the window stock of each region would be growing at the same rate as the national housing stock, which we took to be following the path assumed in the National Energy Strategy (NES 1991). This assumes that the growth in stock falls from 1.3 percent per year in 1992 down to 0.9 percent in 2012 (Table I). Further, we assumed that the window stock decay rate would be 2 percent and that sales would match decay plus growth. We tiven compared the calculated energy loss resulting from two different patterns of window sales through the year 2012. In the first, the mix of technologies currently being sold stayed the same; this assumption effectively characterizes the lower bound of projected gains in window energy efficiency in this period. In the other, only the most energy efficient and cost effective windows were sold - superwindows in the northern states and spectrally selective glazings. in the southern states; this assumption effectively characterizes the upper bound of projected efficiency improvements. In this way, we were able to specify a plausible range in which policy can affect window energy losses. Energy prices of the year 2012 were calculated by assuming that the national energy price rises by fuel type given in the EIA Annual Energy Outlook 1993 applied uniformly to the regional energy prices (EIA 1993, EIA 1992).

In the first case, total residential window energy losses declined only slightly over the two decade period -- by 0.13 quads/year. The improvement of the window stock just counterbalanced the increase in its size (Table J). This nearly static energy loss, however, can be compared to the rising energy use of the US, which has had an average 1.6 percent annual growth over the past decade. Thus, in this static sales scenario, total energy losses through windows declines slightly in magnitude but declines more rapidly as a fraction of national energy expenditures. 
Despite the small decline in energy loss, however, the cost of the lost energy would still climb due to rising energy prices. If sales were to remain static, the cost of lost energy through residential windows would climb to $\$ 31$ billion per year -- a 20 percent rise in monetary costs.

In the more energy efficient scenario, total residential window energy loss drops by 22 percent to 2.2 quads despite the 21 percent increase in the size of the window stock (Table K). By the year 2012, residential fenestration policies can thus aim to achieve a 0.6 quad reduction in our heating and cooling losses, considering only existing technologies. This reduction in energy consumption will little more than counterbalance the expected rise in energy prices, however, as this 2.2 quads in 2012 will come at the same $\$ 25$ billion (1992 dollars) price tag. Thus, unless we see the most stringent regulations on new windows installed combined with encouragements for more retrofits, we will still see a rise in the real cost of energy lost through residential windows.

Figure $\mathbf{P}$ combines these results with information on past window energy losses to show the path that these energy losses have taken over the past two decades and the range in which they are likely to fall in the future. The growing housing stock implied increases in the energy lost through windows, though the use of storm windows and insulating glass has caused the energy losses to start to decline. Much of this decline is attributable to the establishment of fenestration codes requiring minimum U-Values in many states. Without further improvements in the energy performance of windows sold, through more demanding fenestration codes or other market forces, This small decline is likely to stay small. Further advances in the sales of energy efficient windows, however, have a marked potential for decreasing US energy consumption.

Encouragement of more retrofits has the potential to reduce our window energy losses even more the high energy efficient sales scenario, allowing energy losses to fall closer to the technical potential.

\section{Conclusion}

A detailed analysis of the current residential window stock shows that 2.8 quads of energy are being used each year to offset heating and cooling losses through residential windows.. With three percent of our national energy budget devoted to heating and cooling losses through windows in the residential sector alone and \$26 billion per year going to pay the bill, it is important to understand the energy saving potential of new fenestration technologies and how best to design regulations and incentive programs to maximize energy conservation.

The adoption of energy efficient window technologies in homes since 1970 has already resulted in annual energy savings of 0.6 quads -- equivalent to half a percent of our national energy consumption. Existing technologies such as superwindows and spectrally selective glazings have the technical potential to save 2.2 quads per year; at current energy prices, the installation of these technologies would save $\$ 18$ billion per year in energy bills. Window systems now being researched have even greater potential -- the potential to turn a 2.8 quad per year drain into a 1.0 quad per year gain.

Considering only new construction and natural rates of window replacement, strong energy efficiency standards for windows have the potential to reduce annual energy losses due to windows by 20 percent by the year 2012 , despite an expected 21 percent growth in the window stock Given a background of an expected 26 percent rise in energy consumption [EIA 1993] window: thus represent a huge relative opportunity for energy-efficiency improvements. 
These conclusions demonstrate the usefulness of integrating market information with detailed demographic data and an accurate building energy simulation model. This integrated model will be a useful tool with wide applicability for fenestration and energy research.

\section{Future Research}

This project has demonstrated the impact that advanced fenestration technologies have had on US energy consumption in the residential sector and the potential savings yet to be a chieved; it has also defined residential windows' contribution to national energy demand. Much $r$ search remains to be done; future research on this project will include analysis of the commercial sector, the improvement of the data set, improvement and implementation of the market model, and eventual software implementation.

The commercial sector has approximately half as much square feet of windows as the residential sector. Complicating the analysis of this sector, however are the different energy demands of the two sectors. Commercial sector analysis will require a different physical model taking into account the different time-of-day uses of the HVAC system and the lighting savings achievable from such technologies as electrochromics and spectrally selective glazings.

The data set can be improved significantly in a number of ways. Particularly lacking is accurate information on the regional distribution of glazing types in stock and in sales, as well as more disaggregated information of all kinds within regions. California, for example is composed of several distinct climate zones, yet little to no information is available on glazing distributions within California. More localized data would facilitate more accurate energy savings calculations. To this effect, we will pursue three avenues for gathering data. The first will be the distribution of this report to government agencies, industry analysts, and utilities, to encourage feedback on improving the data set or model; the second will be a more thorough survey of state energy agencies for local information on building practices; the third will be a direct survey of builders to determine window types installed by region.

The implementation of the market model also remains. With more accurate local information, the implementation of the market model will give a firmer base from which to forecast energy savings and perform policy analysis.

Finally, with the market model in place, the model will move from spreadsheets into a software package. Software implementation will then facilitate the distribution and use of the model.

\section{Acknowledgment}

This work was supported by the Assistant Secretary for Conservation and Renewable Energy, Office of Building Technologies, Building Systems and Material Division of the US Department of Energy under Contract No. DE-AC03-76SF00098. 


\section{Appendix A: Market Forecasting}

Market Forecasting is a hodge-podge field with many different tools available. These tools vary in effectiveness, applicability, and data requirements.

The most used market models are variations of the following five: judgmental, linear extrapolation, econometric, diffusion, and consumer choice. The "judgmental" model simply asks an expert to make a judgment. In industry, this method is the most commonly used form of market forecasting. Using individual judgment and intuition has its obvious advantages and drawbacks. The advantage is the experience of the forecaster in the field and a lack of restriction to any particular mathematical tool. The disadvantage is that the method is only as good as the judge. In a sense, what any mathematical model attempts to do is to codify proven expert techniques; a mathematical model tries to reproduce an expert on a floppy disk or spread sheet. However, this task is often futile, because once the code is written, it is fixed and can no longer adapt to new experience and information. Our computer model will be designed as a tool for the expert "judge" -- to help inform the expert and to allow the expert to better codify his or her experience. With this objective in mind, it is necessary to examine the formalized models of market dynamics in order to choose the most appropriate modeling framework for the residential window market.

A linear extrapolation is the crudest form of mathematical modeling of markets. In its simplest form it simply entails drawing a line through the past data into the future; as such, it is relatively low in detailed data demands. Linear extrapolation is fair enough for either a steadystate market or one in which change is occurring at a known, constant rate; this description does not, however, apply to the window market, as many technologies either have only just emerged in the market or will do so in the future, creating a dynamic and unstable market.

The econometric model is one of the most data-intensive models. By measuring a linear elasticity (change) for demand and supply with respect to a number of variables, like income, cost, and price, it creates a foundation for projecting where price, supply, and demand will go with small perturbations in these variables. "Small perturbations" is the key phrase, here; with any significant change in any variable related to the market, a new market environment is produced.

The actual nonlinearities of real world supply and demand relations make the linear predictions of an econometric model of decreasing relevance and the large data acquisition necessary for the model of vanishing worth. Because we do not have the data for a detailed econometric model and, more importantly, because we are interested in large changes in the market, an econometric model is also inappropriate.

The diffusion model rests on the observation that adoption of new, cost effective technologies does not occur instantaneously, as assumed by microeconomic theory, but follows, roughly, a logistic curve: first, a few innovators pick up the technology; then, as others observe that the new technology can work, they become reassured and adopt the technology themselves, increasing demand and decreasing price through economies of scale. More consumers then purchase the new product at the economy-of-scale price until the market nears saturation, and sales stabilize at replacement rates. The data requirements and mathematical detail of the diffusion model are less cumbersome than those of the econometric model; one must estimate the potential market for the technology, which in the case of new windows is some subset of the total window market, and use historical data to estimate the speed of the logistic acceptance. A 
diffusion model is limited, however, as it is based on an aggregate phenomenon and thus is not applicable to the prediction of individual purchases.

Discrete consumer choice models come in a wide variety of complexities and formats.

The most simple is the neoclassical microeconomic model, which assumes that the consumer is all-knowing and perfectly rational according to economic standards and makes decisions according to a straightforward cost-benefit analysis. As this model makes no attempt to model dynamic market effects and fails to straightforwardly account for non-price variables, it is unsuitable by itself for market forecasting [Stern 1986, Lutzenhiser \& Hackett 1991]; however, its implied framework of cost-benefit analysis is a useful tool for estimating market potentials.

A new generation of models takes more sophisticated psychological dynamics into account. One of these models is the logit model [Cowing and McFadden 1984]. Motivated by the fact that consumer choices do not fall strictly into line with the micro economists' cost-benefit analysis, logit models postulate tha: the consumer has a desirability function, similar to the utility function in the traditional micro framework, which, instead of indicating what is definitely chosen, gives a probabilistic weighting to the consumer's choices. The consumer then uses a random decision-making process, with probabilities weighted by the exponentiated desirability function. In application, this explanation of consumer choice appears to be ad hoc and is often simply used to avoid having to model a heterogeneous population, highly non-uniform in their decision criteria. If one ignores the explanation of dynamics and derives a tautological desirability function for a given population from the observed market behavior, then one can ask the question, "Will this model be adequate for predicting future market dynamics?" This case is similar to the case of deriving linear elasticity functions from market behavior and using an econometric model; for small changes in the market, the model will work well enough, but if the market is dynamic -- as the residential fenestration market now is -- then the predictions of the model will diverge quickly from what's observed because of a lack of foundation in actual dynamics. The market is not characterized by one uniform decision criterion, but by a collection of heterogeneous decision makers.

Other discrete decision models, called adoption process models, attempt to root their modeling in the details of the decision-making process, accounting for the different stages in the mental process of adopting a technology and how societal factors may affect these steps differently [Kendall and Cates 1991]. They typically divide the decision making process into a number of steps. An example divides the market population into a set of consumer mental states regarding the technology: Unaware, Aware, Adopting, and Not Adopting. There will then be an associated matrix which specifies the probability that someone in a particular state will transform into another state; the coefficients of the matrix are estimated from historical data. The flow of population into the Adopting state is equivalent to sales.

In choosing what kind of model to use, it is important to consider the data requirements of the model, the data available, and the context for use of the model. In this case, data are available on yearly sales of different window and frame types from AAMA, NAHB, and NWWDA, and some limited information on window stock is available from RECS, aggregated to the federal region level. Cost data can be obtained from NAHB [Koomey et al 1991] or by doing some phone shopping (leading to the odd observation that prices vary by orders of magnitude for the same product from one source to another). More detailed information may in the future be obtained by contractor and home owner surveys, but a yearly supply of such surveys would be necessary to warrant the use of the econometric or logit type models on grounds of increased 
accuracy. More important, however, is the intended audience of the model. The complexification of models works in the opposite direction of communication, toward obfuscation. A survey of the literature on econometrics or logit analysis releases a dense pile of mathematica. Lacking a clear presentation of the derivation of the results, however, the decision maker is left to either have blind faith in the results or to blindly doubt them. It is important for the process of forecasting to be communicable to the decision maker, along with the results.

For reasons of data availability and communicability of process, we use a diffusion-based model for market forecasting; we use historical analogy to set diffusion rates and a combination of historical, psychological, and microeconomic analysis to estimate market potentials. Such a model will be more versatile in accommodating users' experiential knowledge of market behavior and be less obscured by unnecessary and inappropriate mathematical complexity.

\section{Appendix B: Calculation of Database Parameters from Existing Data}

The first step in the process of calculating the energy implications of windows is the characterization of the window stock. In the optimal case, we would know exactly where all of the windows were, what the climate was like in the area, and how people behave with regards to window installation and use; then, if we had unlimited computing time, we would model each window separately. However, we have neither such specific data nor such amounts of computing time, so the inputs must be aggregated to a level appropriate for the data sources and the research resources. To facilitate calculation, the window stock was broken down into a number of distinct sub populations characterized by particular climates and socio-economic environments -- the most relevant socio-economic factor being building code applicability. Each sub-population was then be treated as a separate unit in calculation. The particular sub-populations have been chosen to reflect available data and magnitude of window sales.

The data are available at many levels of aggregation. On the one hand, the Statistical Abstract offers some data at the state level. On the other hand, some of the data necessary for the project are only available from RECS at the level of the Four Federal Census regions. For the purposes of this study, information will be aggregated to the level of twelve regions (Figure 0 ). These regions correspond to the nine Federal Census sub-regions, with finer detail given for California and Florida and a splitting of the Mountain States Region into two regions. This choice reflects the wide use of these approximate breakdowns of the states in many data sources, the large window sales (and therefore relevance of window technologies' impacts) in both Florida and California, and the necessity of treating parts of the Mountain Region separately, because of extreme climate variations across the region. The choice to neglect Aiaska and Hawaii resulted from the lack of data on window sales in these states and their small window stocks, estimated at less than one percent of the total US window stock. In future studies aggregated at the state level, these states should be included. Where significant differences exist between states within a given study region, they will be effectively disaggregated by applying separate calculations to different fractions of the study population but will be aggregated in output results. Again, in future studies at the state level, these differences will be reflected in the more disaggregated outputs. 


\section{Total Window Area}

There is no one existing source which claims to characterize the window stock in the US, so an approximation of the stock had to be derived from figures available from a number of data sources. The number of households is available by state from the Statistical Abstract, and the average square feet per household is available from RECS by Federal Census region. To translate these figures into the window stock, one must know the relationship between square feet of floor area and window installation. This relationship is by no means straightforward, but a rough cut can be made by estimating the average area of installed window per area of constructed floor space. Estimates of window area per housing unit range between the equivalent of ten and twenty percent of floor area, depending on the location, builder, and building type. Some more precise estimates in the Northwest have been done by the Northwest Power Planning Council [NPPC 1990]. The NPPC estimates range from 10 percent in Montana to 17 percent in Oregon, indicating that the warmer the state, the higher the glazing fraction. Also, figures are available from Huang et. al, broken down by housing type [Huang et. al. 1991]. Given figures for window to floor ratio estimated from these sources, one can then estimate the total glazing area by study region illustrated in Figures $\mathrm{L}$ and $\mathrm{M}$. Taking California as an example, the Statistical Abstract gives the figure of 10 million households while RECS gives a figure of $1600 \mathrm{sq} \mathrm{ft}$ per single-family home, $910 \mathrm{sq} \mathrm{ft}$ per multi-family home, and $1000 \mathrm{sq} \mathrm{ft}$ per mobile home. Estimating an average of 17 percent glazing to floor fraction in single family homes and 13 percent in multi-family and mobile homes, this gives 2.0 billion sq $\mathrm{ft}$ of windows in the California housing stock. The other regions' window areas were calculated similarly. From the uncertainties in each of these figures, an error bound of plus or minus 10 to 20 percent is reasonable on these window stock magnitudes.

Characterizing the details of the window stock composition is a more difficult task. RECS has figures by Census region on how many windows per state have glazing better than single glazing (including storm windows) for 1987, but for greater detail on glazing type and any detail on frame type, extrapolations must be made from past sales and construction data. Regional sales data exists by frame type from both NWWDA and AAMA. Given the total sales of vinyl frames and thermally broken aluminum frames from national level data and the past local ratios of aluminum to wood sales, an estimate of the frame composition by state can be made. However, these sales figures are in window units, not in square feet of window surface, as the stock figures are. The simplest way to translate these figures into square feet is to multiply the window units by the mean area per window unit, estimated to be roughly 12 square feet, though this figure varies region to region and vintage to vintage.

\section{Frame types}

As an example, California has a window stock of approximately 2.0 billion sq $\mathrm{ft}$. NWWDA's regional data, in 1990 show that California accounted for approximately 1.7 percent of vinyl frame sales. Extrapolating this percentage to past sales, which total to 45 million units, and assuming average window size of $12 \mathrm{sq} \mathrm{ft}$, this implies a California vinyl window stock of 16 million sq $\mathrm{ft}$. As vinyl frames have only been on the market for a little more than a decade, about a third of the average window life span, the finite life span of the window can be ignored in calculating the stock from sales. Similarly, 90 percent of the sales of aluminum frame with 
thermal breaks have been made in the last decade, so the life span question can be ignored. A similar calculation then gives 110 million sq $\mathrm{ft}$ of thermally broken aluminum frames.

An estimate of aluminum and wood frame stocks can then be made by assuming that the ratio of the stocks of aluminum frames to wood frames is equal to the ratio of the average yearly sales (equivalent to assuming that the life spans of the frames are the same). However, regional data only exists for 1988-1990 in the NWWDA study, so the use of the average flow of this period will disguise previous variations in the flow. National data exist for the 1968-1991 period from AAMA, and the mean ratio of aluminum sales to wood sales over this period was 1.3 , as opposed to the same ratio from the same data, taken over the 1988-1990 period, which is 0.69 . From the NWWDA data, the mean ratio of sales in California was 6.6. Adjusting for the longer term variations in aluminum and wood window sales evident from the AAMA data gives a ratio of 10. Thus, given the total window stock, the constitution of that stock is estimated as 1.7 billion sq $\mathrm{ft}$ of aluminum frames without thermal breaks, 110 million sq $\mathrm{ft}$ of thermally broken aluminum frames, 190 million sq $\mathrm{ft}$ of wood frames, and 16 million sq $\mathrm{ft}$ of vinyl frames.

\section{Glazing Types}

Very little data exist on local sales of advanced glazing systems. The most detailed data come from NAHB for single-family detached home construction. NAHB gives the average number of glazing layers installed in 1987 by state, as was illustrated in Figure $H$. The survey, though, has problems with small data sets and states with few or no responses. Further, because it surveys only new construction, it does not necessarily represent most of the market. Advanced glazing systems have only had a recent history, however, national data are available for all of their sales and these sales over the years can be summed to get the total amount installed. A reasonable estimate of the distribution of advanced glazing can then be calculated by assigning location to the advanced glazing stock based on the window stocks of the regions weighted by the NAHB advanced glazing sales data (alternatively, the RECS storm window installation figures could be used, but different dynamics cause the installation of advanced glazing systems and storm windows, as is evidenced by California's exceptionally low storm window installation rate and rather high rate of installation for windows with multiple glazing layers). Because the NAHB results have shown an anomalously high figure for double or better glazing in the South Atlantic Region, this data point was thrown out and the average of Florida and the Mid Atlantic region was used for the South Atlantic area.

The results of calculations for the glazing systems and frame types by region are illustrated in Figures L and M. Storm window distribution derived from RECS data is illustrated in Figure $\mathrm{N}$. For practicality, it was assumed that storm windows were applied randomly across the window stock. There may, however, be a stronger weighting toward less efficient glazing systems, so some small error in the resulting energy calculation may be found from this assumption. The residential window stock resulting from these calculations is given in Table L.

\section{Appendix C: Brown, Arasteh, and Eto}

In 1991, Brown, Arasteh, and Eto compared the energy savings implications of two policies having the effects of 25 percent and 90 percent market penetration, respectively, of advanced fenestration systems by the year 2005. In the North Central federal region, which is 
heating dominated, the appropriate technology was determined to be the superwindow, a triple glazed window with two low-e coatings, argon fill, and a highly insulating frame. In California, most growth is projected to occur in the Central Valley where cooling is more of a concern, so the appropriate technology was determined to be a double glazed window with argon fill, spectrally selective glazing, and an insulating frame.

Using PEAR, a DOE2 regression model similar to RESFEN, and reasonable assumptions about the volume of window sales and size of the window stock in these regions, the yearly energy savings from the use of advanced technology windows was calculated. For the North Central federal region, it was found that the savings from avoided cooling energy was negligible, but that the heating savings were significant. Moreover, the energy efficiency policy case of 90 percent market penetration led to an energy savings of 2 TBtu per year by 2005, as opposed to the "no policy" case, leading to an energy savings of only $0.4 \mathrm{TBtu}$. The benefit to cost ratio for the superwindow varied by heating type, but using 1988 energy prices and a seven percent discount rate, it was found to be 1.2 for gas heating, 2.1 for homes with heat pumps, and over 4.3 for electrically heated homes ( a benefit-cost ratio of greater than one implies that from an economic perspective, a project should be undertaken).

Similarly, using PEAR and applying the results to California, there were found to be significant savings from converting to new technologies. There were significant cooling savings 1.2 TBtu/yr and $0.3 \mathrm{TBtu} / \mathrm{yr}$ for the efficiency policy case and no policy case respectively-, but the big savings was found to be in heating energy. The no policy case led to a heating energy savings of 1.2 TBtu/yr, but the efficiency policy case had the effect of inducing a savings of $6.4 \mathrm{TBtu} / \mathrm{yr}$. The differences in the savings in these two regions is large, but has more to do with the size of the housing market and housing stock than with the effectiveness of the technologies. Again, the benefit to cost ratio varied in Califi nia from one heating and cooling system to the next, but they were, in all three examined fuel types, greater than one. 


\section{References}

American Architectural Manufacturers Association (AAMA), Industry Statistical Review and Forecast, AAMA, Des Plaines II (1979 - 1991)

AAMA. Study of the Residential Window and Skylight Markets, AAMA, Des Plaines IL (1988)

Arasteh, D., Super Windows How two layers of low-E coating + Krypton/Argon =R7, Glass Magazine, p82 (May 1989)

Arasteh, D., S. Selkowitz, and J. Hartmann. Detailed Thermal Performance Data on Conventional and Highly Insulating Window Systems, LBL-20348, Lawrence Berkeley Laboratory, Berkeley (1988)

American Society of Heating, Refrigeration, and Air-Conditioning Engineers (ASHRAE), 1989 ASHRAE Handbook: Fundamentals, ASHRAE, Atlanta, GA (1989)

Azon USA Inc., 'The Use of High Density Polyurethane Thermal Barriers in Architectural Aluminum Extru.ions in the USA From 1975 to 1989, Azon, Kalamazoo, MI (1991)

Barbee, Look Homeward, Glaziers, Glass Magazine (December 1988)

Brown, R., D. Arasteh, and J. Eto, 1992. Improving the Thermal Performance of the US Residential Window Stock, Lawrence Berkeley Laboratory, Berkeley (1992)

Bureau of the Census, Statistical Abstract of the United States: 1991, Bureau of the Census, Washington, DC (1991)

Cowing, T., and D. McFadden, Microeconomic Modeling and Policy Analysis, Academic Press Inc., Orlando, FL (1984)

Cunningham, R., New Decade Brings New Challenges to the Industry, Glass Digest, (January 1991)

Department of Energy, National Energ Strategy Technical Annex 2, US DOE, DOE/S-0086P, DC (1992)

Dodge/Sweet, Dodge/Sweet's Construction Outlook 1992, Dodge/Sweet, NY NY (1992)

Energy Design Update. Argon Low-e Windows Contimue to Gain Importance in 1988, (December 1989)

Energy Design Update, Low-e, High Sales, (February 1992) 
Energy Information Administration, Annual Energy Outlook 1993, US DOE, DOE/EIA0383(93), DC (1993)

Energy Information Administration, Residential Energy Consumption Survey: Housing Characteristics 1987,, Energy Information Administration, US DOE, DOE/EIA-0314(87), Washington, DC (1989)

Energy Information Administration, State Energy Price and Expenditure Report 1990, DOE/EIA -0376 (90), Washington, DC (1992)

Energy Information Administration, Energy Facts 1990, DOE/EIA-0469(90), Washington DC (1990)

Huang, J. et al.. Multifamily Heating and Cooling Requirements: Assumptions, Methods, and Summary Results and Single-Family Heating and Cooling Requirements: Assumptions, Methods, and Summary Results, GRI-91/0236, Lawrence Berkeley Labs for Gas Research Institute (1991)

Kendall, D., and S. Cates, 1991. Market Penetration of New Technologies, Programs, and Services, EPRI CU-7011, Research Triangle Institute, NC

Koomey, J., J. McMahon, and C. Wodley, Improving the Thermal Integrity of New Single Family Detached Residential Buildings: Documentation for a regional database of Capital Costs and Space Conditioning Load Savings, LBL-29416, Lawrence Berkeley Laboratory (1991)

Lutzenhiser, L., and B. Hackett, Social and Engineering Models of Consumption: An Empirical Examination, University of California Energy Research Group, Davis, CA (1989)

National Conference of States on Building Codes and Standards (NCSBCS), Energy Directory, NCSBCS, Herndon, VA (1991)

Northwest Power Planning Council (NPPC), personal communication on RCDP and RSDP studies of window area to floor area ratios in the NW states for new homes (1991)

National Wood Window and Door Association (NWWDA), Housing Activity and Frame Materials Demand, NWWDA (1990)

Reilly, M., D. Arasteh, and M. Rubin, The Effects of Infrared Absorbing Gasses on Window Heat Transfer: A Comparison of Theory and Experiment, LBL-29389, Lawrence Berkeley Laboratory, Berkeley (1989)

Selkowitz, S., Window Performance and Building Energy Use: Some Technical Options for Increasing Energy Efficiency, LBL-20213, Lawrence Berkeley Laboratory, Berkeley (1985)

Selkowitz, S., Smart Windows, Glass Magazine, p86 (August 1986) 
Schuman, J., Cool Daylight, Progressive Architecture, (April 1992)

Stern, P., Blind Spots in Policy Analysis: What Economics Doesn't Say about Energy Use, Journal of Policy Analysis and Management, 5, No 2, John Wiley \& Sons inc. (1982)

Sullivan, R., Draft: RESFEN 1.0: A Prototype PC Program for Calculating Residential Fenestration Heating and Cooling Energy Use and Cost, LBL-31176, Windows and Daylighting Group, Lawrence Berkeley Laboratory, Berkeley (1991)

US DOE, Residential Energy Consumption Survey: Housing Characteristics 1987,, Energy Information Administration, US DUE, DOE/EIA-0314(87), Washington DC (1989)

Warner, J., Consumer Guide to Energy-Saving Windows, Home Energy Journal (1990)

Weidt, J.L., and J. Weidt, Air Leakage of Newly Installed Residential Windows, LBL-11111, Lawrence Berkeley Laboratory, Berkeley (1980)

Windows and Daylighting Group, Window 4.0: A PC Program for Analyzing Window Thermal Performance, LBL-32091, Lawrence Berkeley Laboratory, Berkeley (1992) 
Figure A: Thermal Transfer through a Window

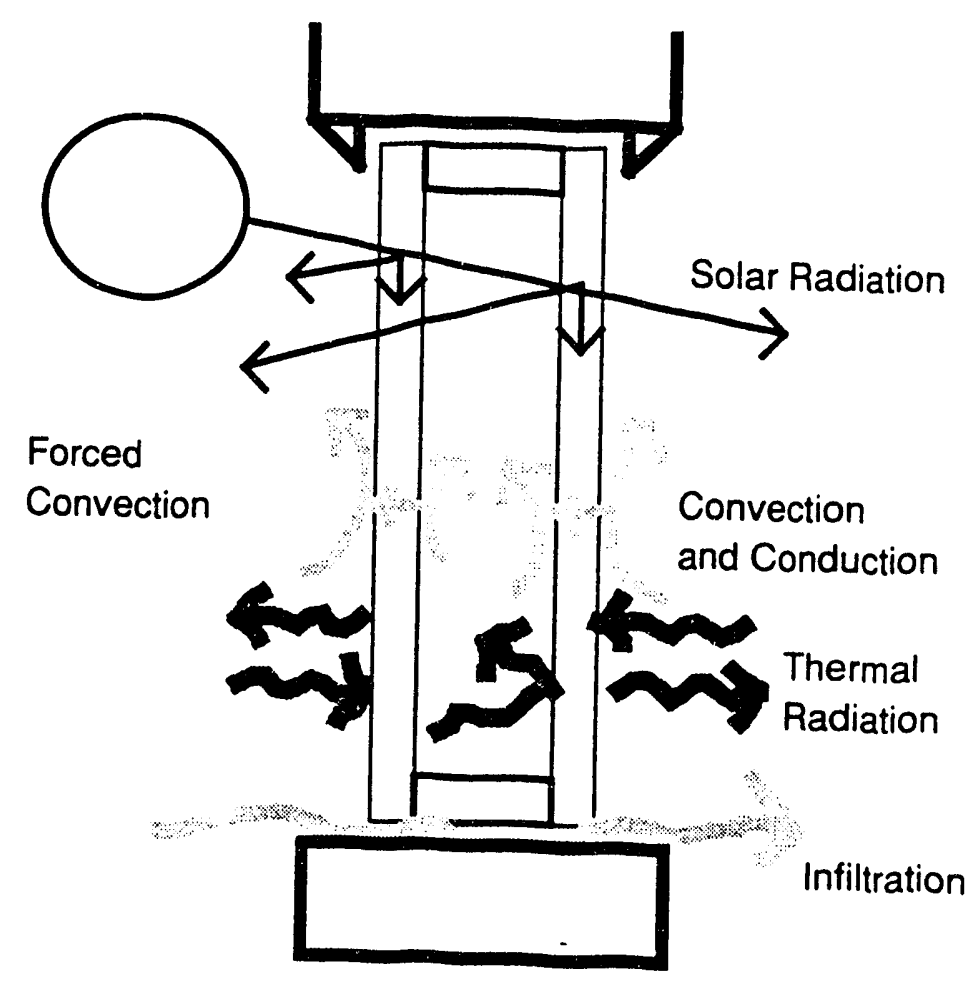




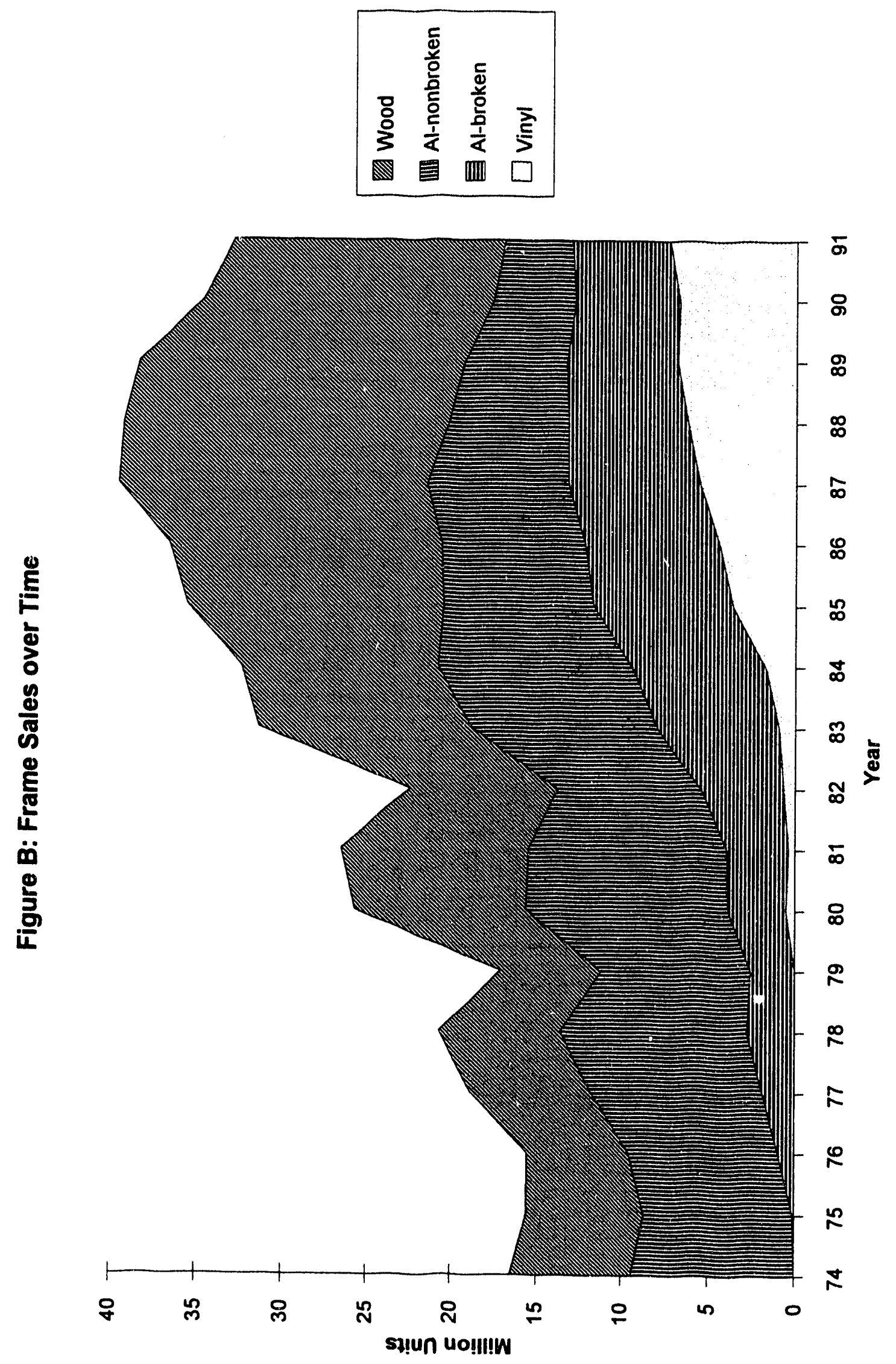




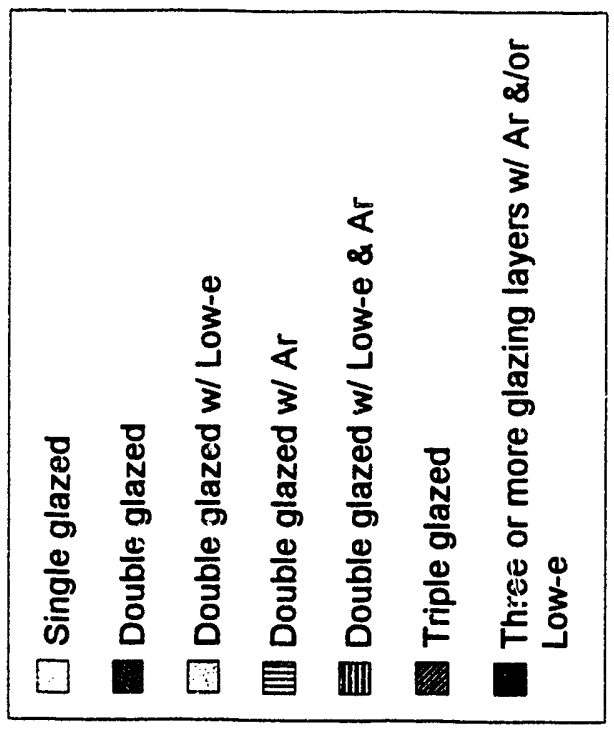

$\frac{6}{6}$

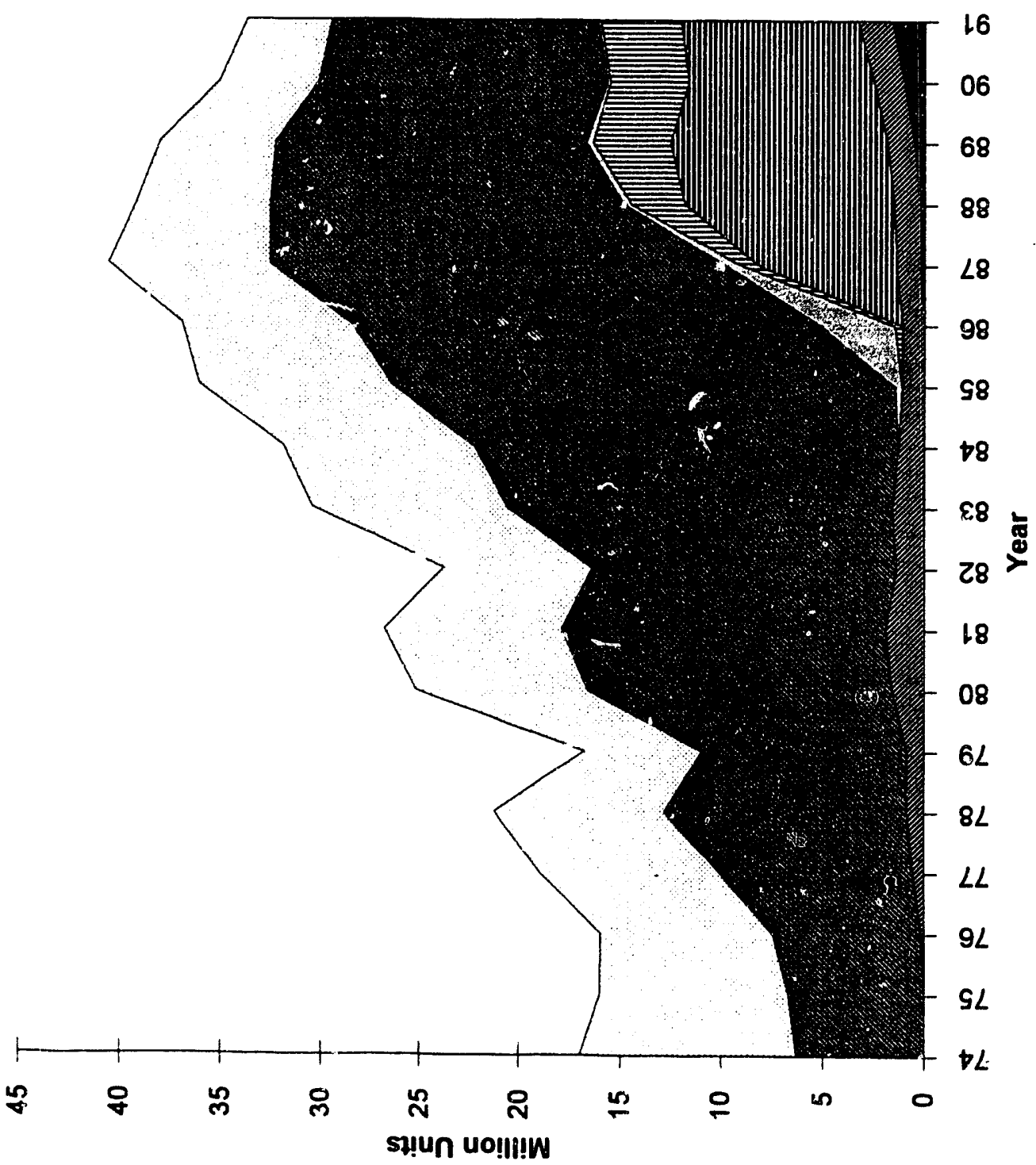



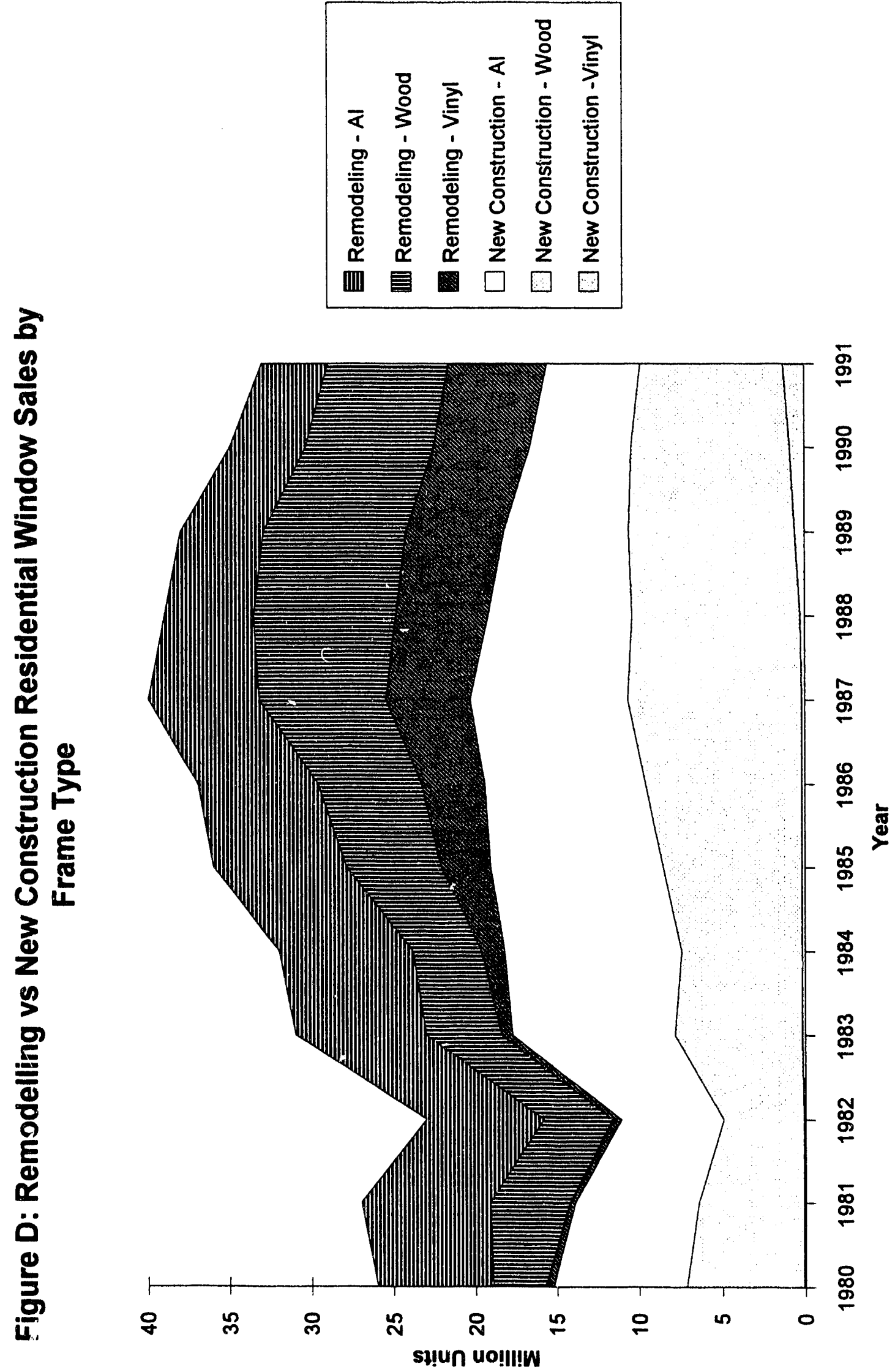


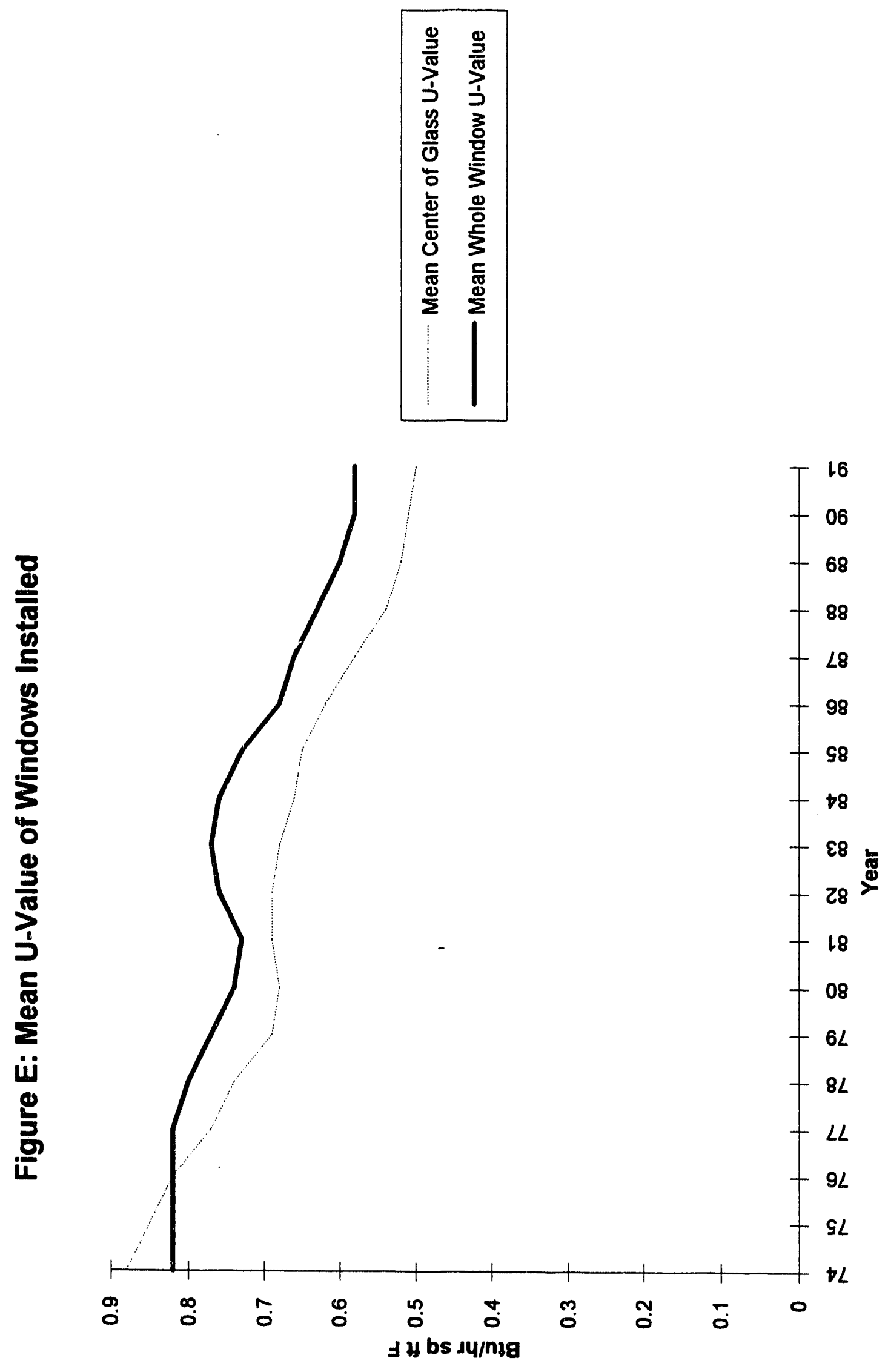




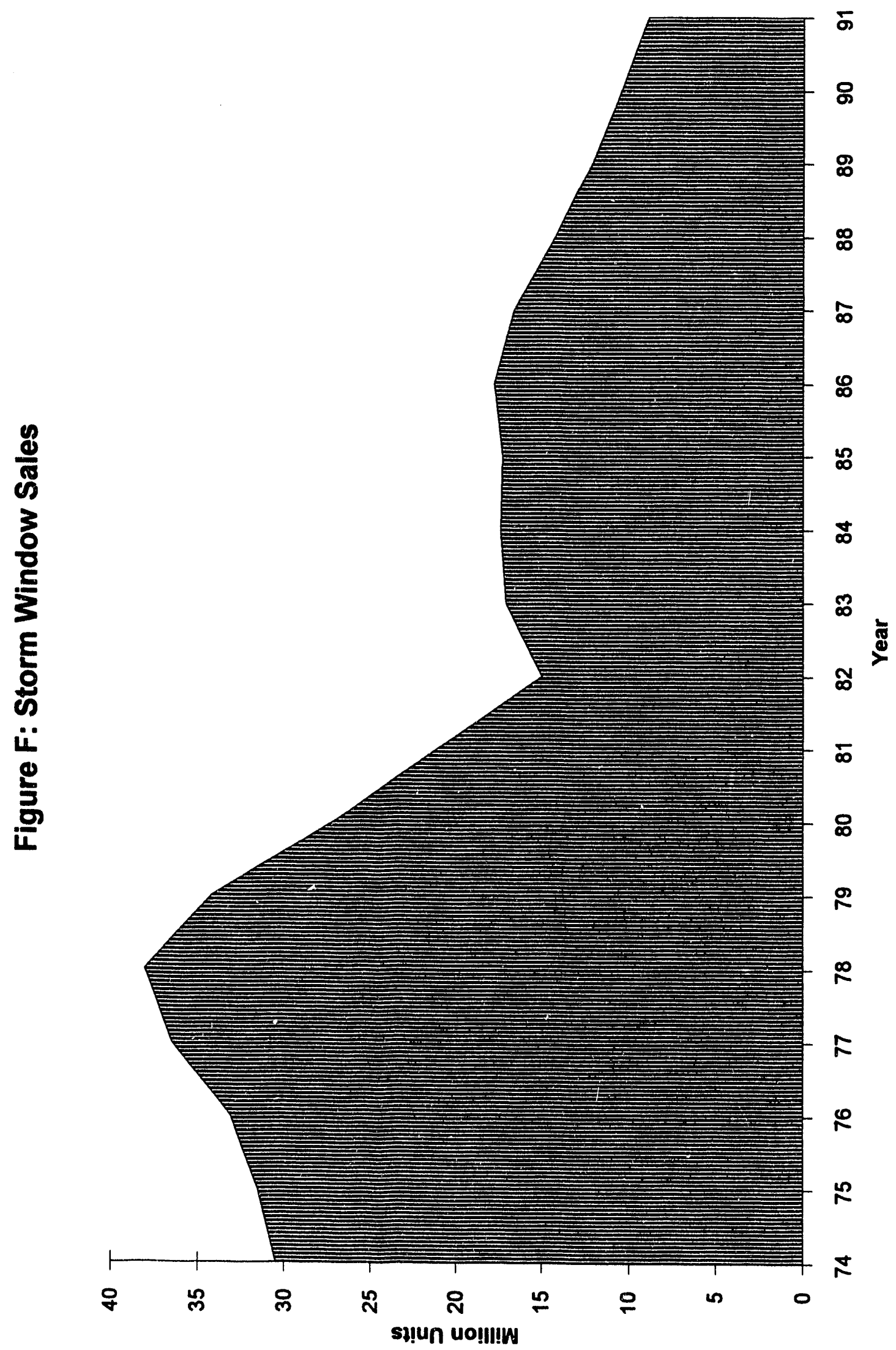




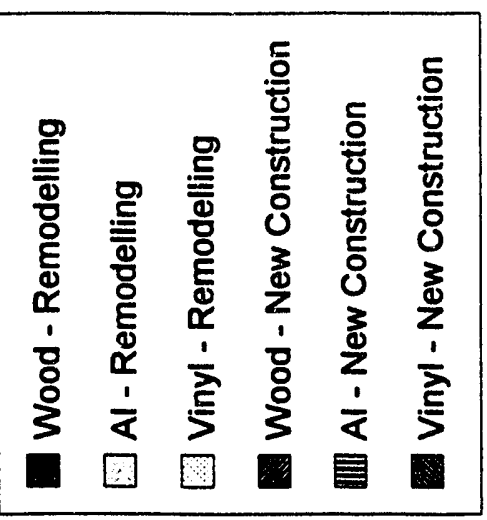

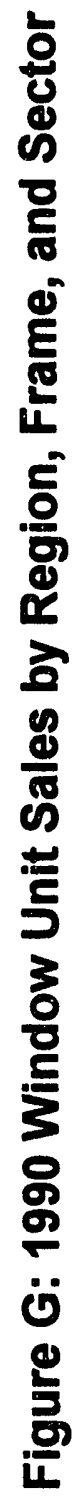

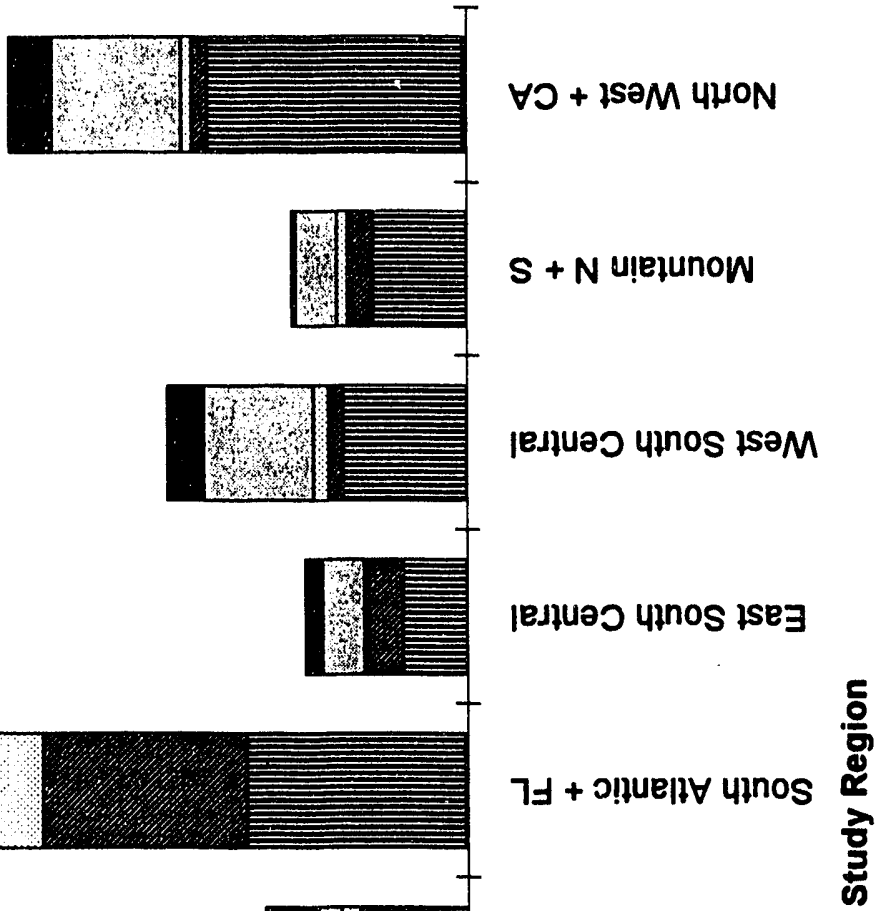

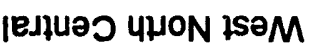

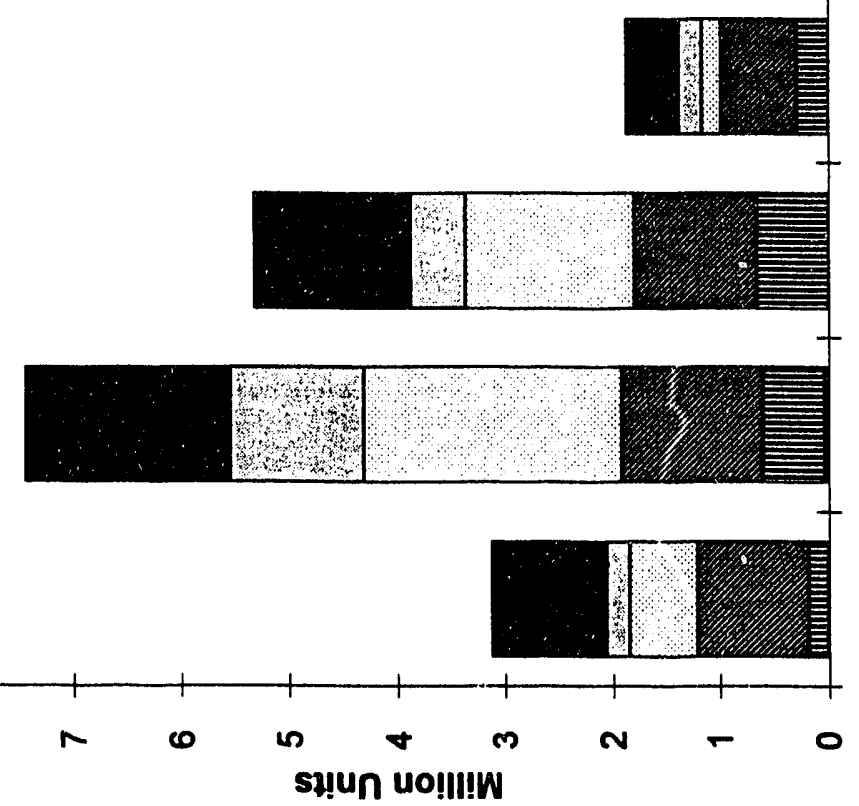

ןEJ\}U一כ YHON ISE

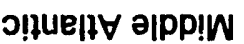

pUe|6uت MON 


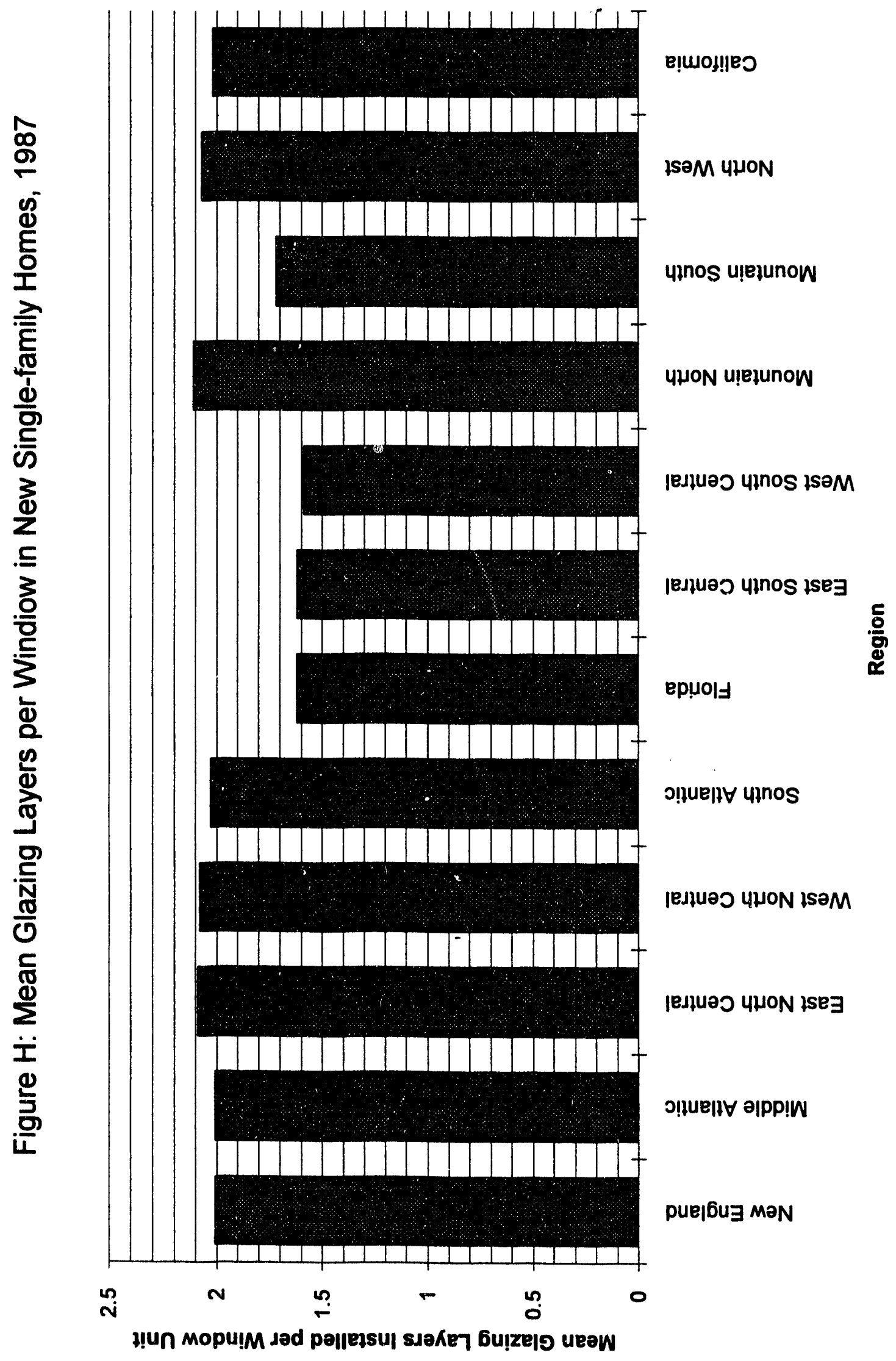



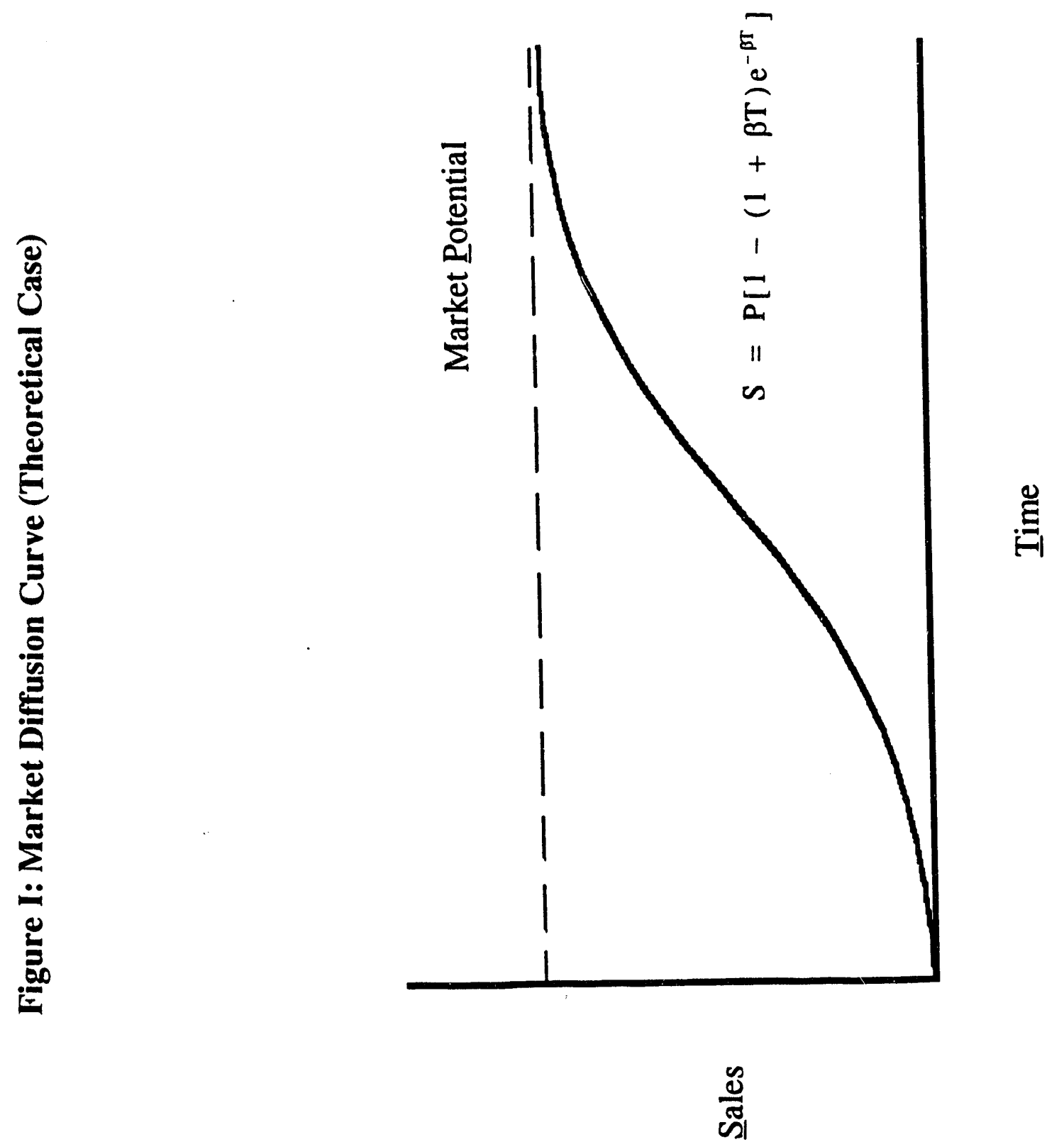


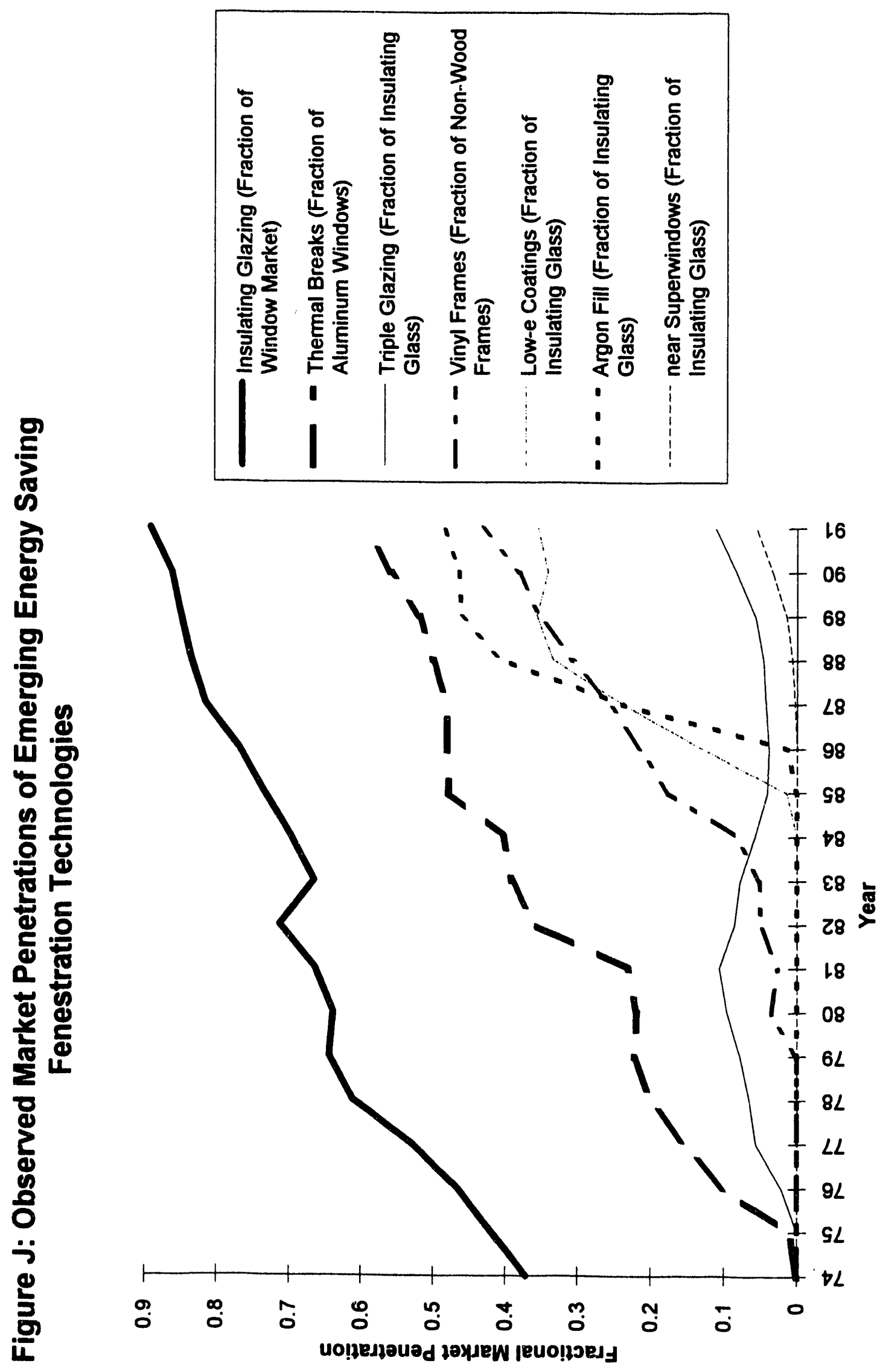




\section{Figure K: Window Energy Conservation Model Flow Chart}

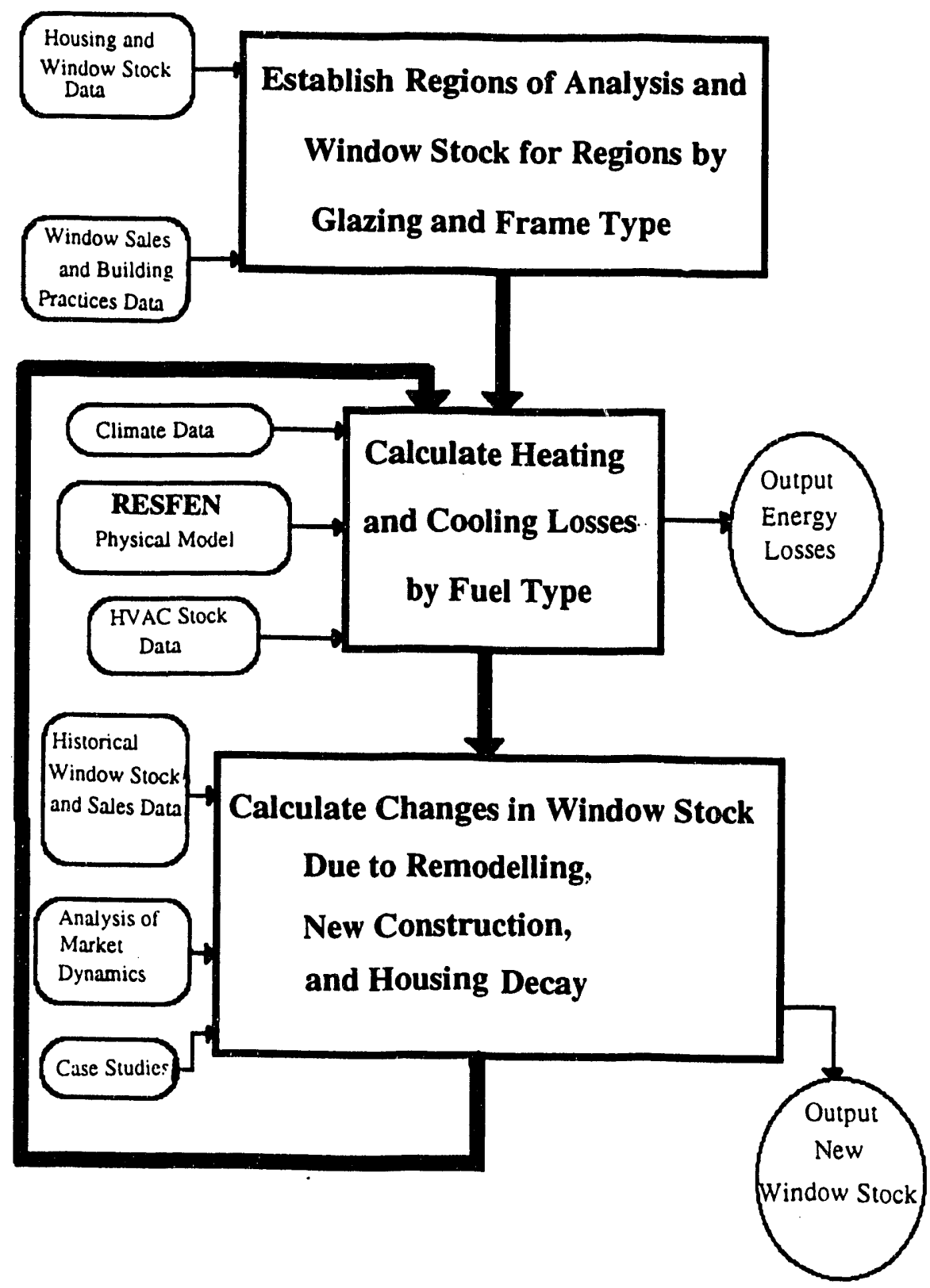




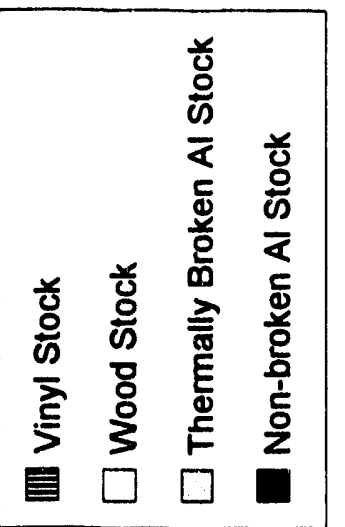

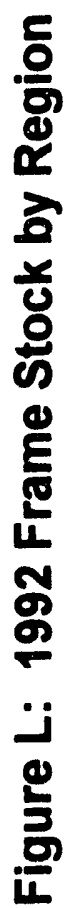

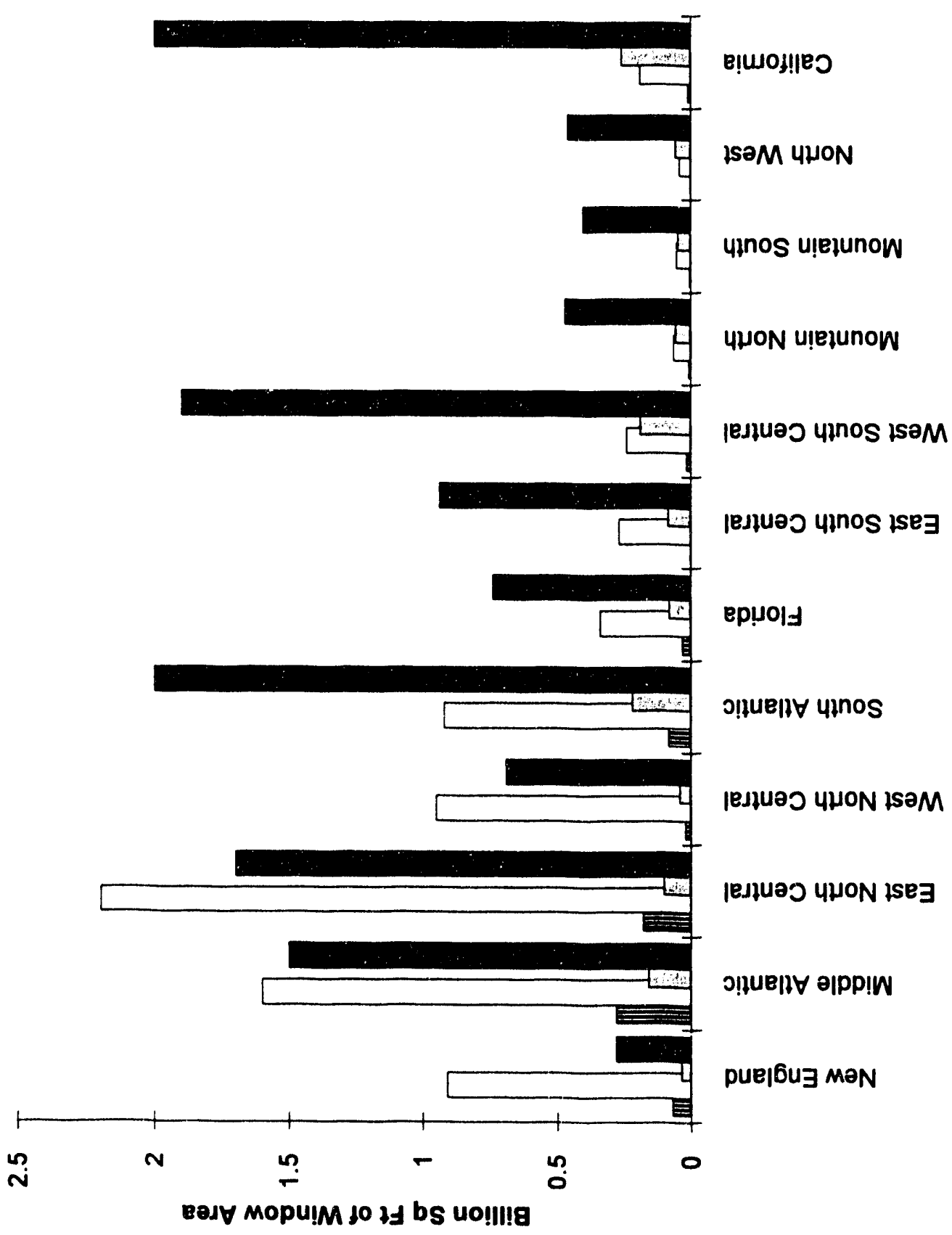


Figure M: 1992 Glazing Stock by Region

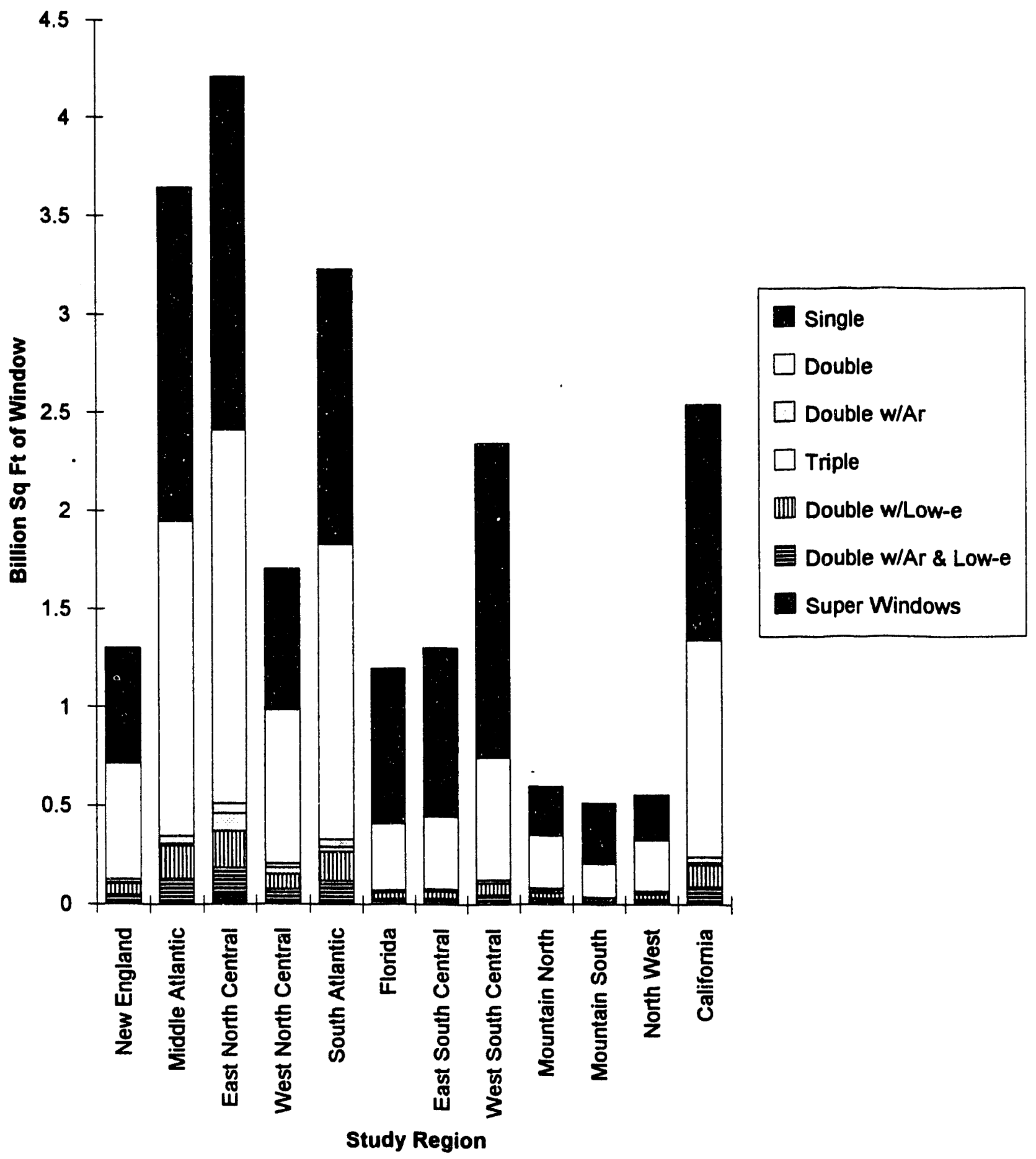



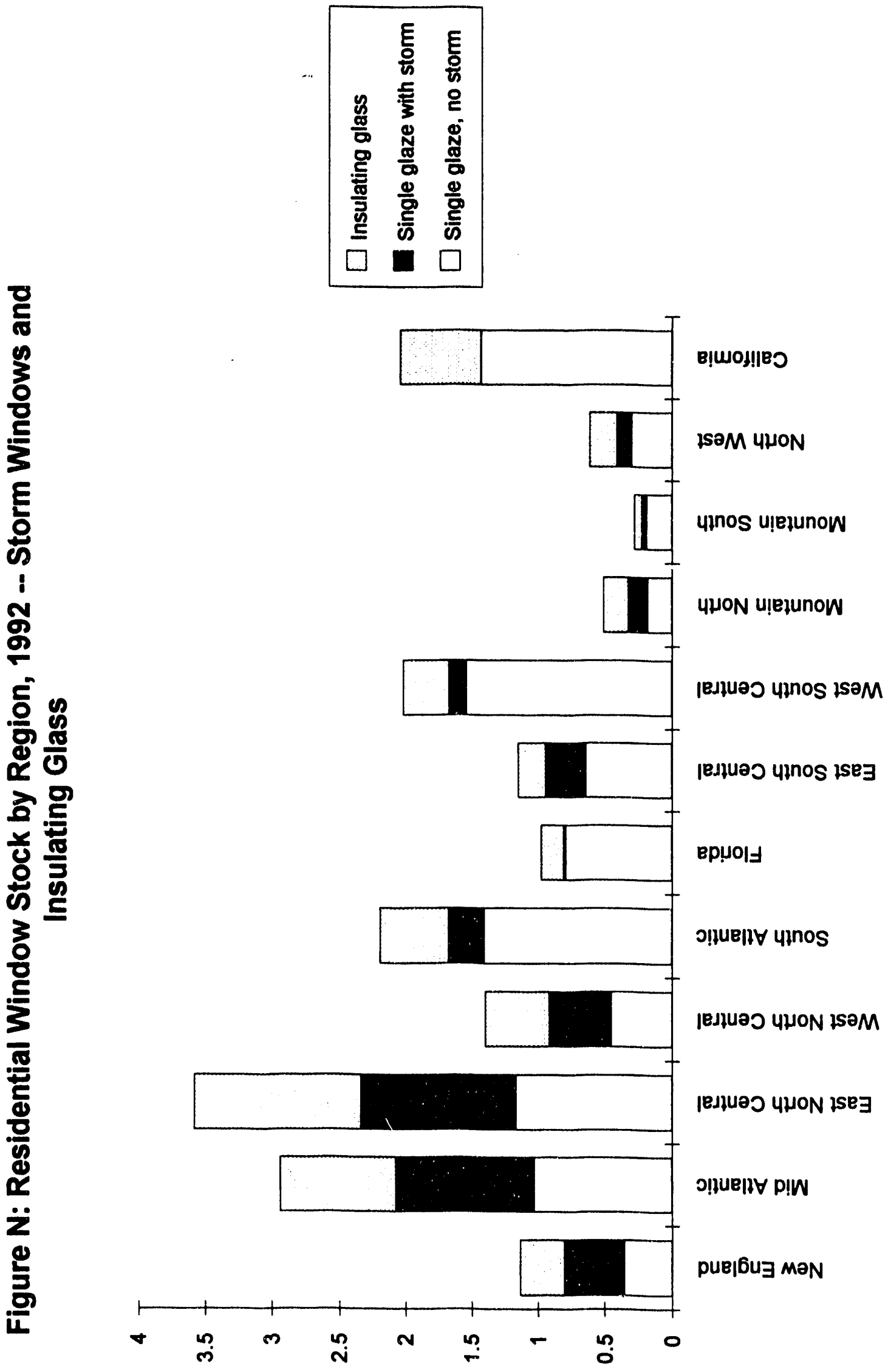


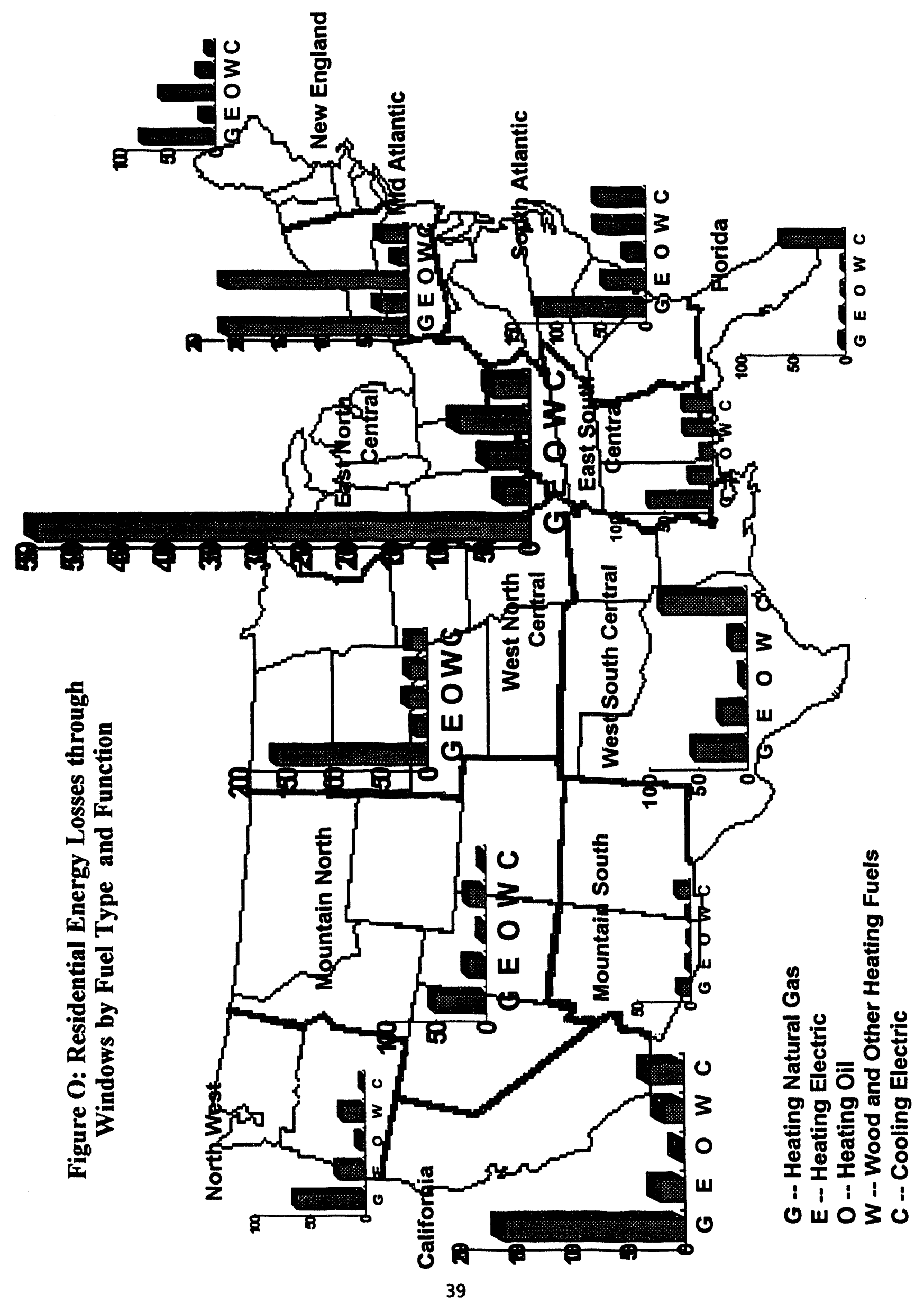



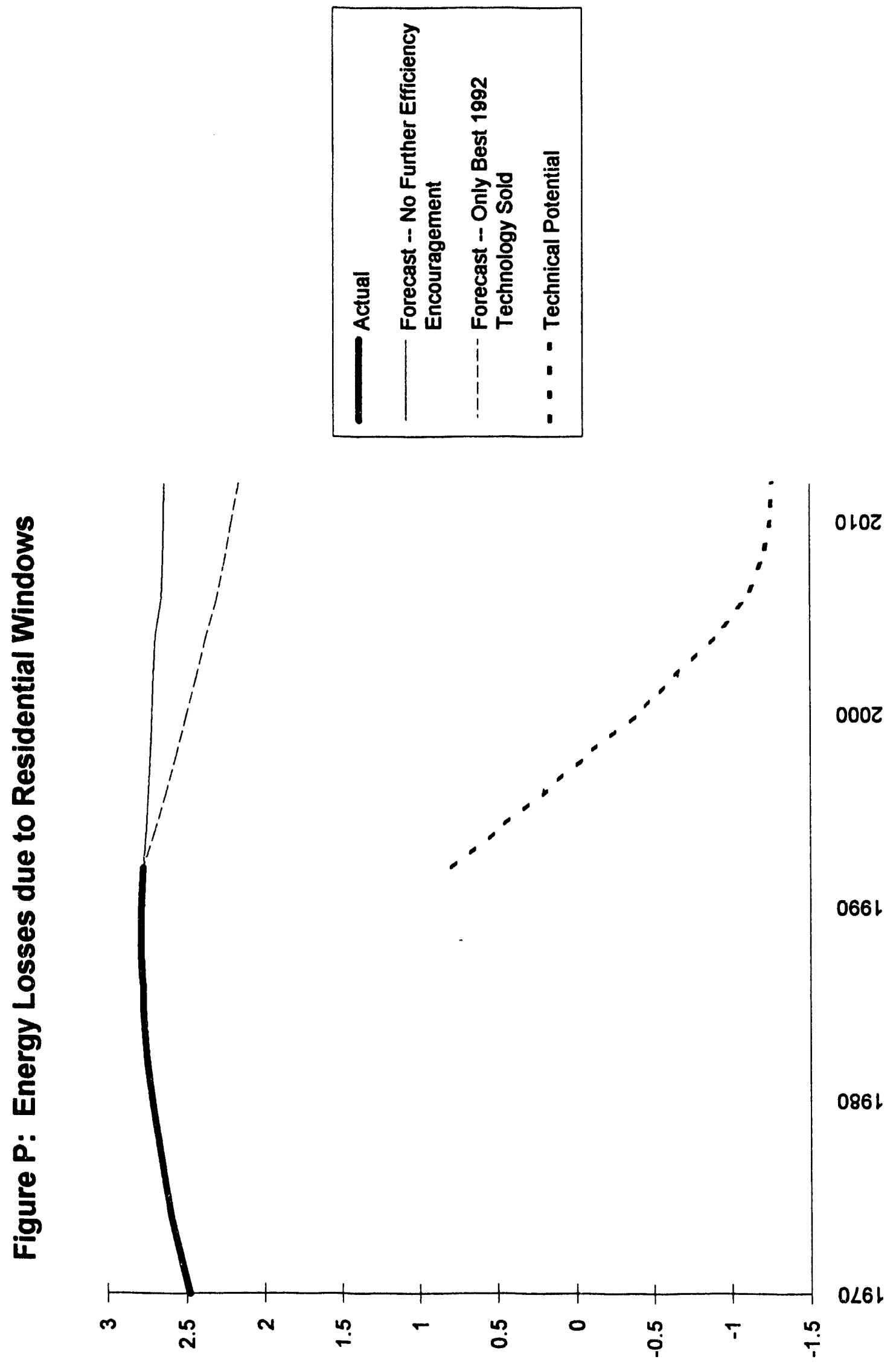


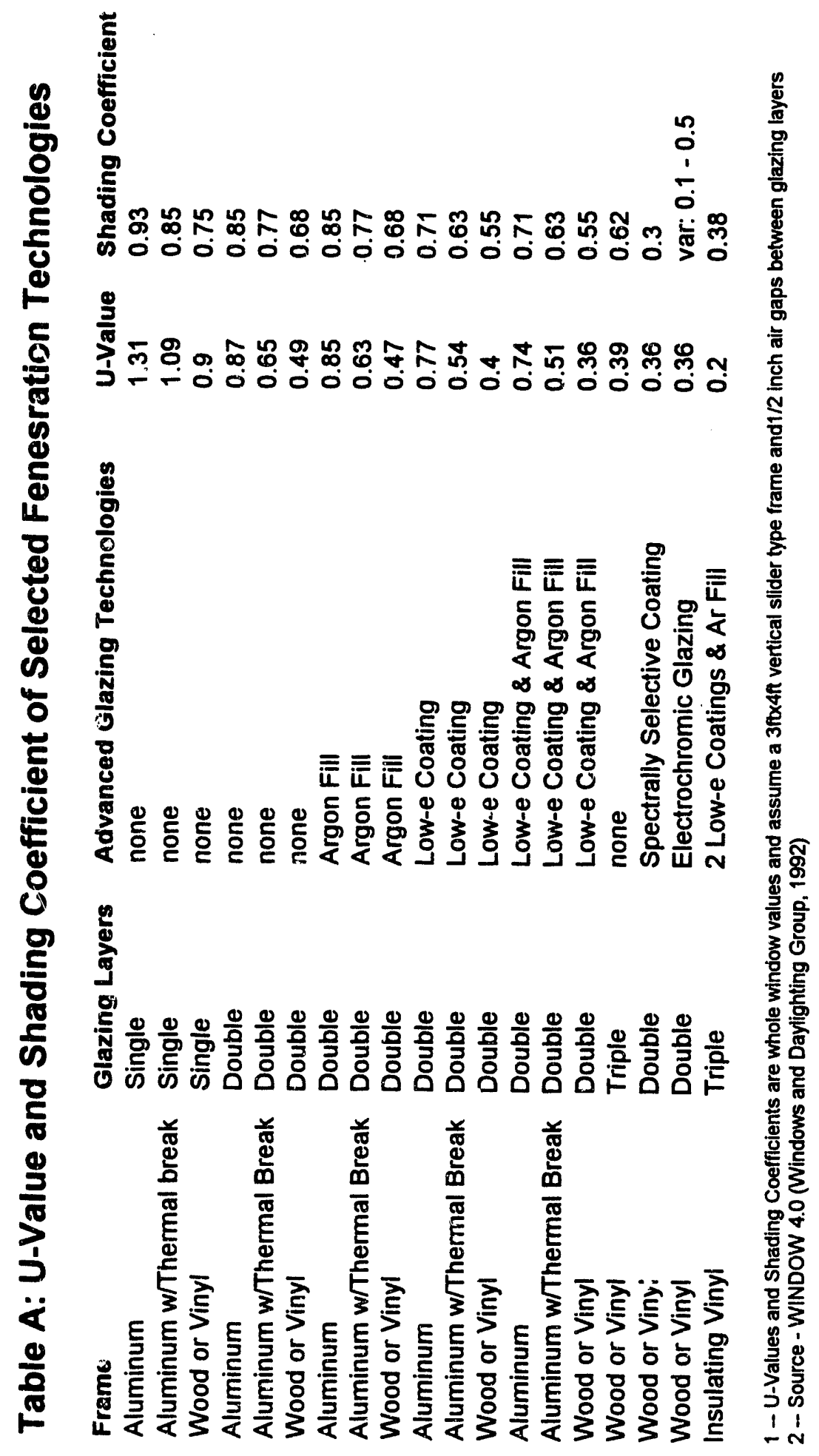


Table B: US Residential Fenestration Sales, 1974 to 1991

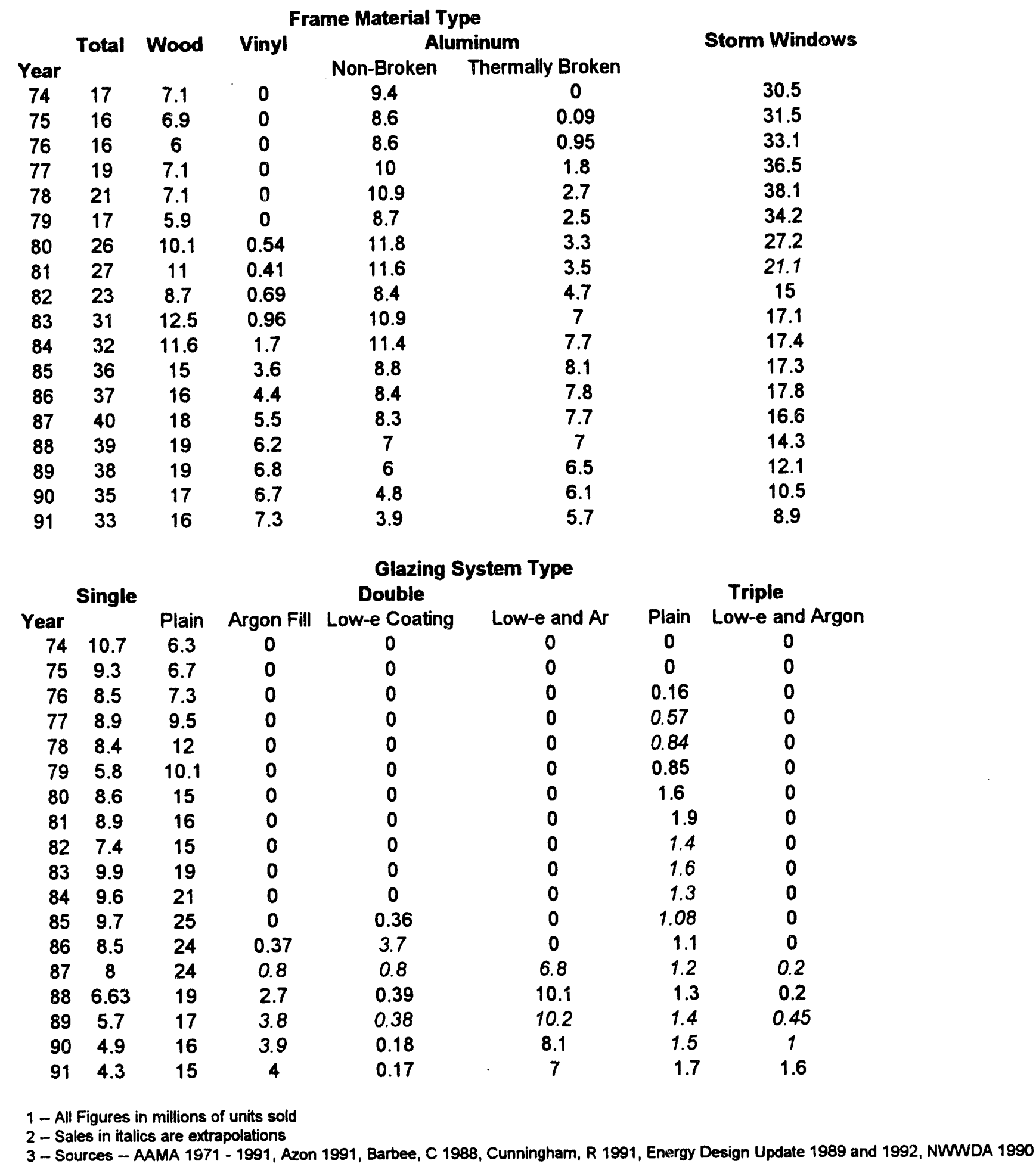




\begin{tabular}{|c|c|c|c|c|c|c|c|}
\hline \multirow[b]{2}{*}{ Region } & \multicolumn{5}{|c|}{ Heating Equipment } & \multicolumn{2}{|c|}{ Cooling Equipment } \\
\hline & Gas & Electric & Heat Pump & Oil & Other & Air Conditioner & Heat Pump \\
\hline New England & 0.44 & 0.09 & 0.005 & 0.4 & 0.11 & 0.46 & 0.005 \\
\hline Middle Atlantic & 0.4 & 0.09 & 0.04 & 0.5 & 0.02 & 0.66 & 0.04 \\
\hline East North Central & 0.74 & 0.06 & 0.01 & 0.1 & 0.12 & 0.68 & 0.01 \\
\hline West North Central & 0.74 & 0.06 & 0.01 & 0.1 & 0.09 & 0.68 & 0.01 \\
\hline South Atlantic & 0.42 & 0.18 & 0.11 & 0.1 & 0.21 & 0.82 & 0.11 \\
\hline Florida & 0.46 & 0.32 & 0.09 & 0 & 0.09 & 0.88 & 0.09 \\
\hline East South Central & 0.42 & 0.18 & 0.11 & 0.1 & 0.21 & 0.85 & 0.11 \\
\hline West South Central & 0.42 & 0.32 & 0.09 & 0 & 0.13 & 0.87 & 0.09 \\
\hline Mountain North & 0.49 & 0.26 & 0.03 & 0 & 0.18 & 0.24 & 0.03 \\
\hline Mountain South & 0.74 & 0.11 & 0.05 & 0 & 0.09 & 0.44 & 0.05 \\
\hline North West & 0.49 & 0.26 & 0.03 & 0 & 0.18 & 0.24 & 0.03 \\
\hline California & 0.74 & 0.11 & 0.05 & 0 & 0.09 & 0.44 & 0.05 \\
\hline
\end{tabular}

Source - RECS 1989

\section{Table D: Efficiency of Heating and Cooling Equipment Stock}

$\begin{array}{lc}\text { Heating Fuel } & \text { Stock Energy Efficiency Ratio * } \\ \text { Electric } & 3.4 \\ \text { Gas } & 0.672 \\ \text { Oil } & 0.758 \\ \text { HP } & 5.676\end{array}$

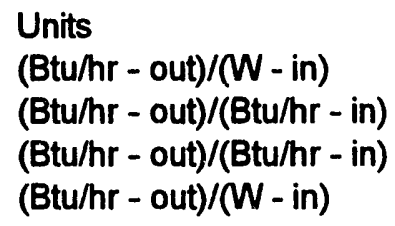

Cooling Equipment

AC

8.2
8.4

(Btu/hr - out)/(W - in)

HP

(Btu/hr - out)/(W - in)

" = not including duct losses, estimated at $30 \%$

Source - LBL-REM 1992 


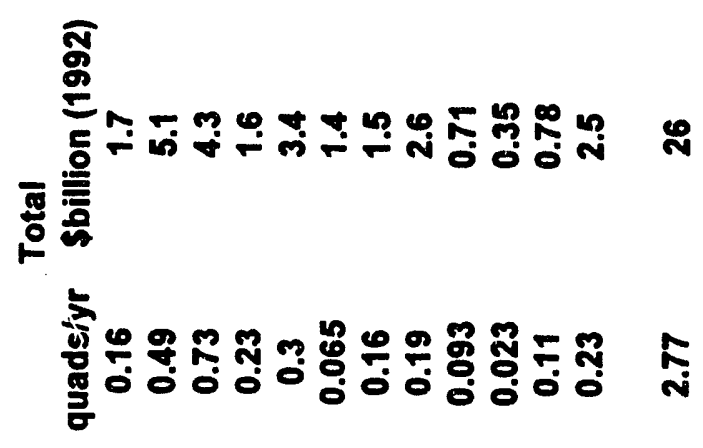

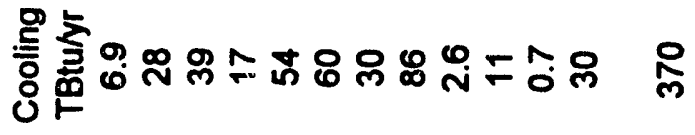

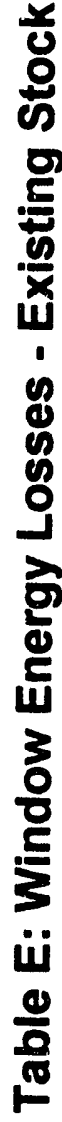

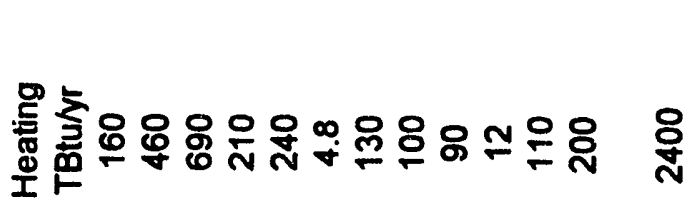

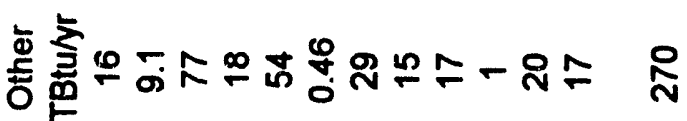

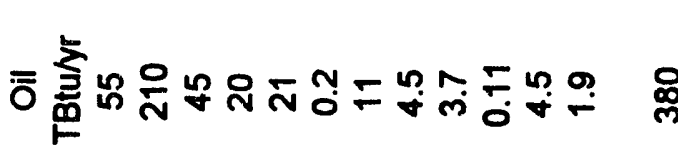

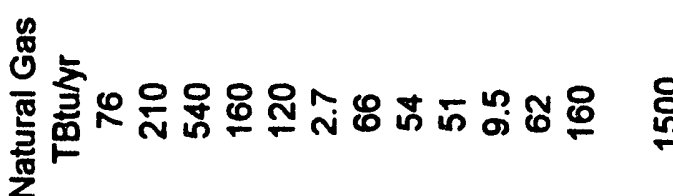

는

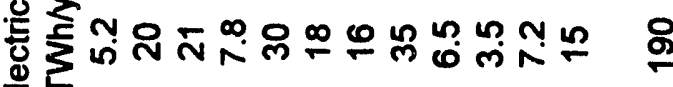
พ

을

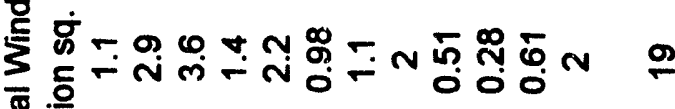

졸

옹

용

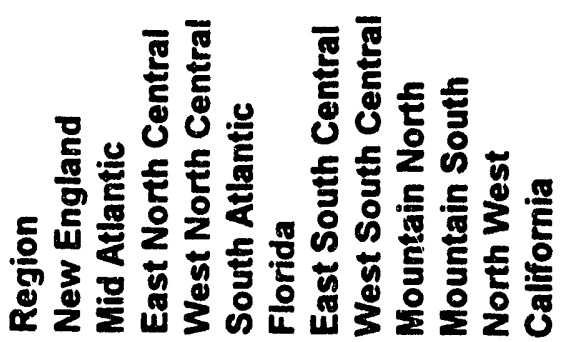




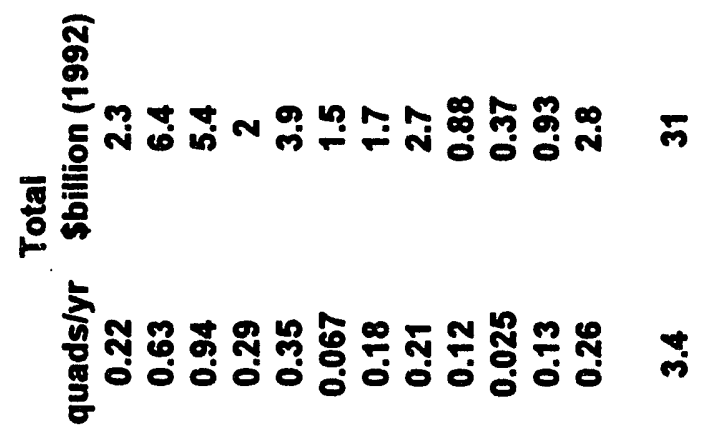

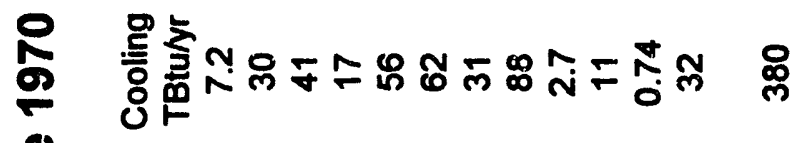

造

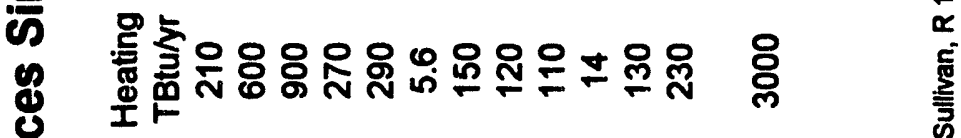

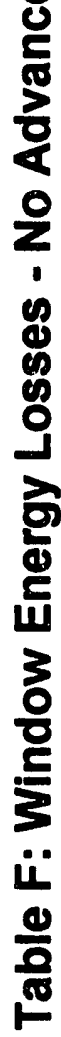

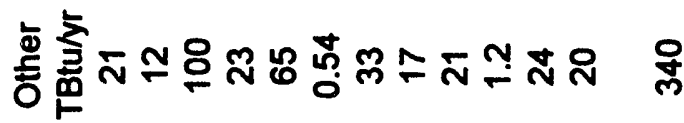

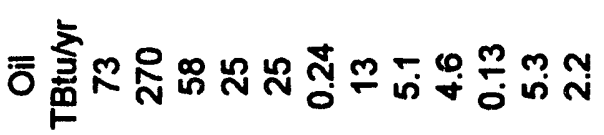

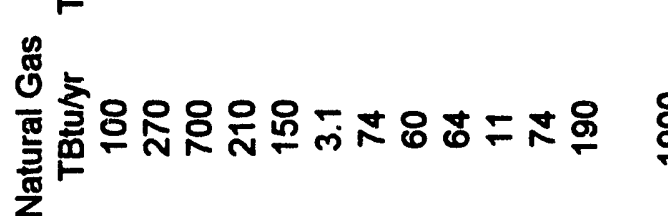

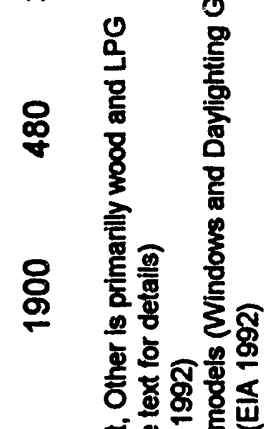

논

定

รั่

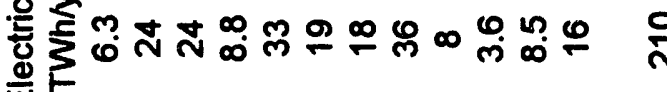
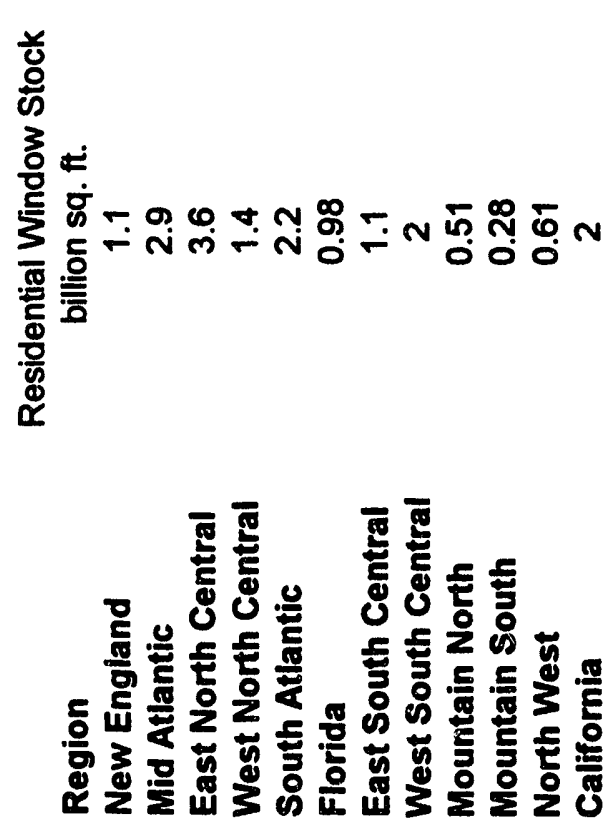

은

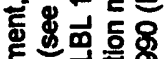

을

ब्ञ

등 형 훙

8 \%

额视

오용

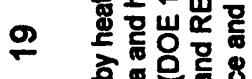

过

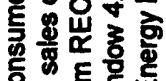

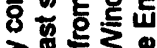
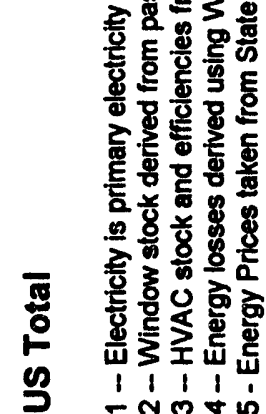


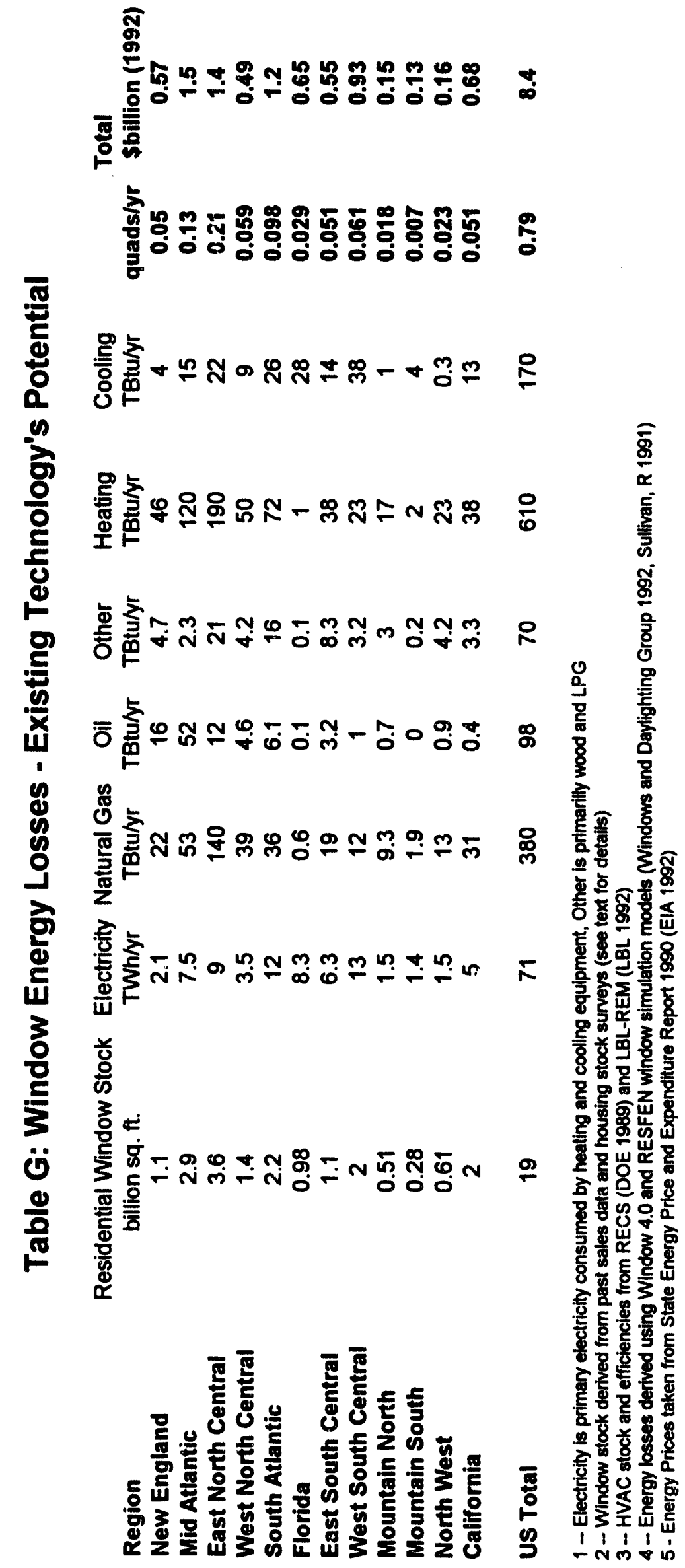




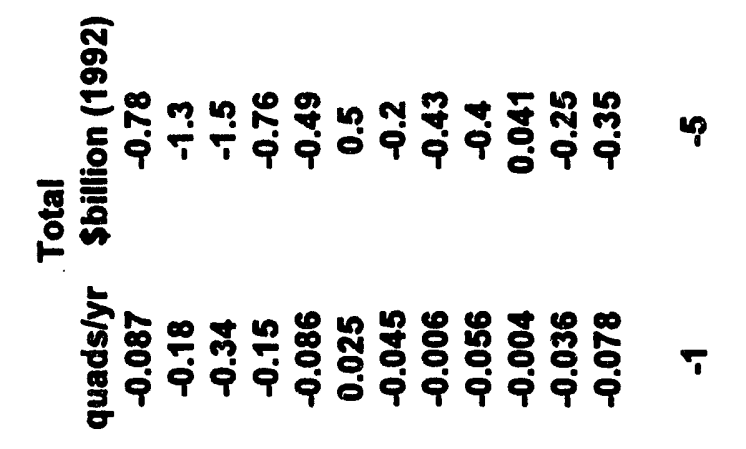

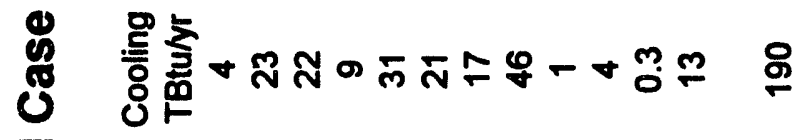

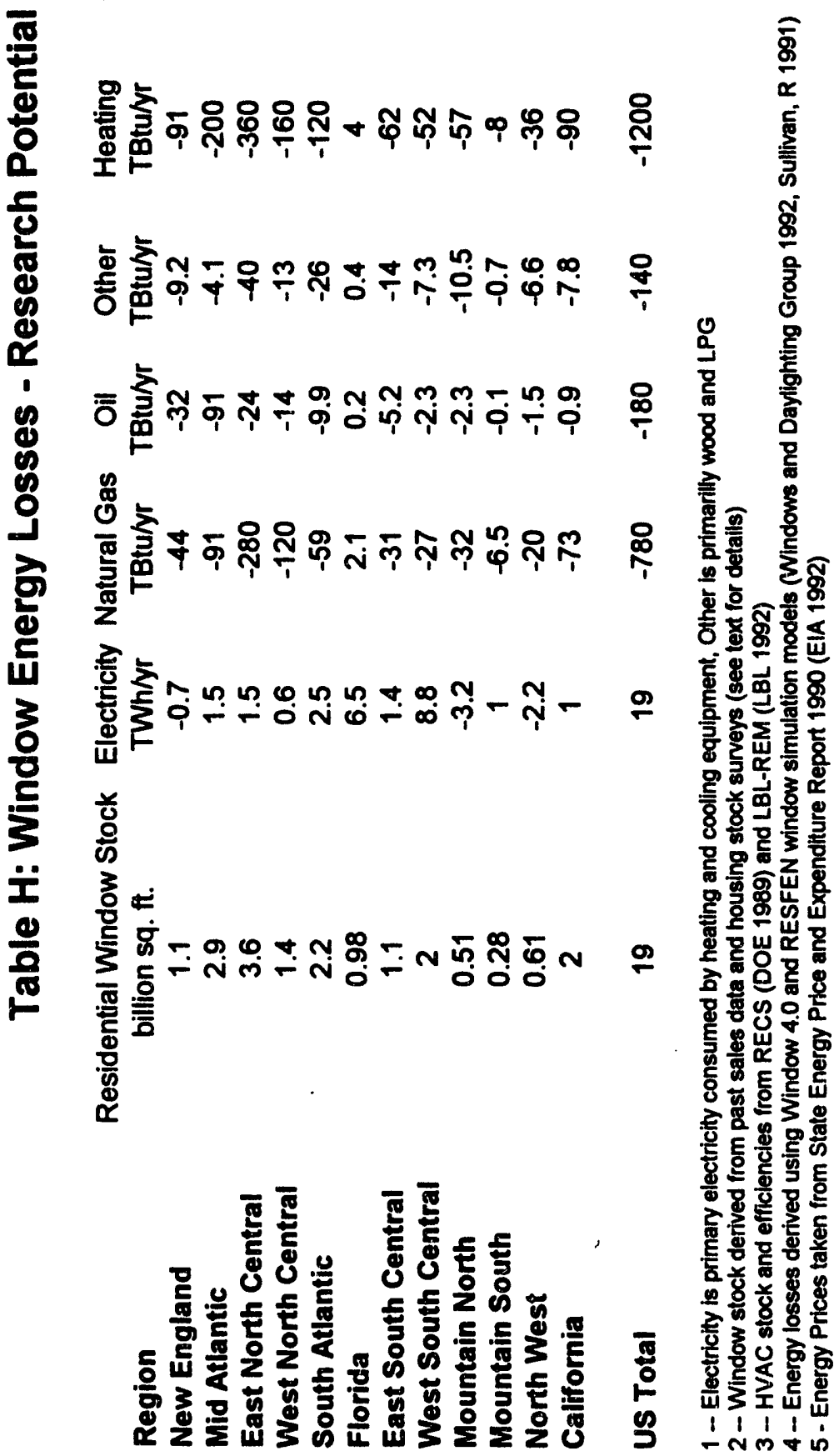




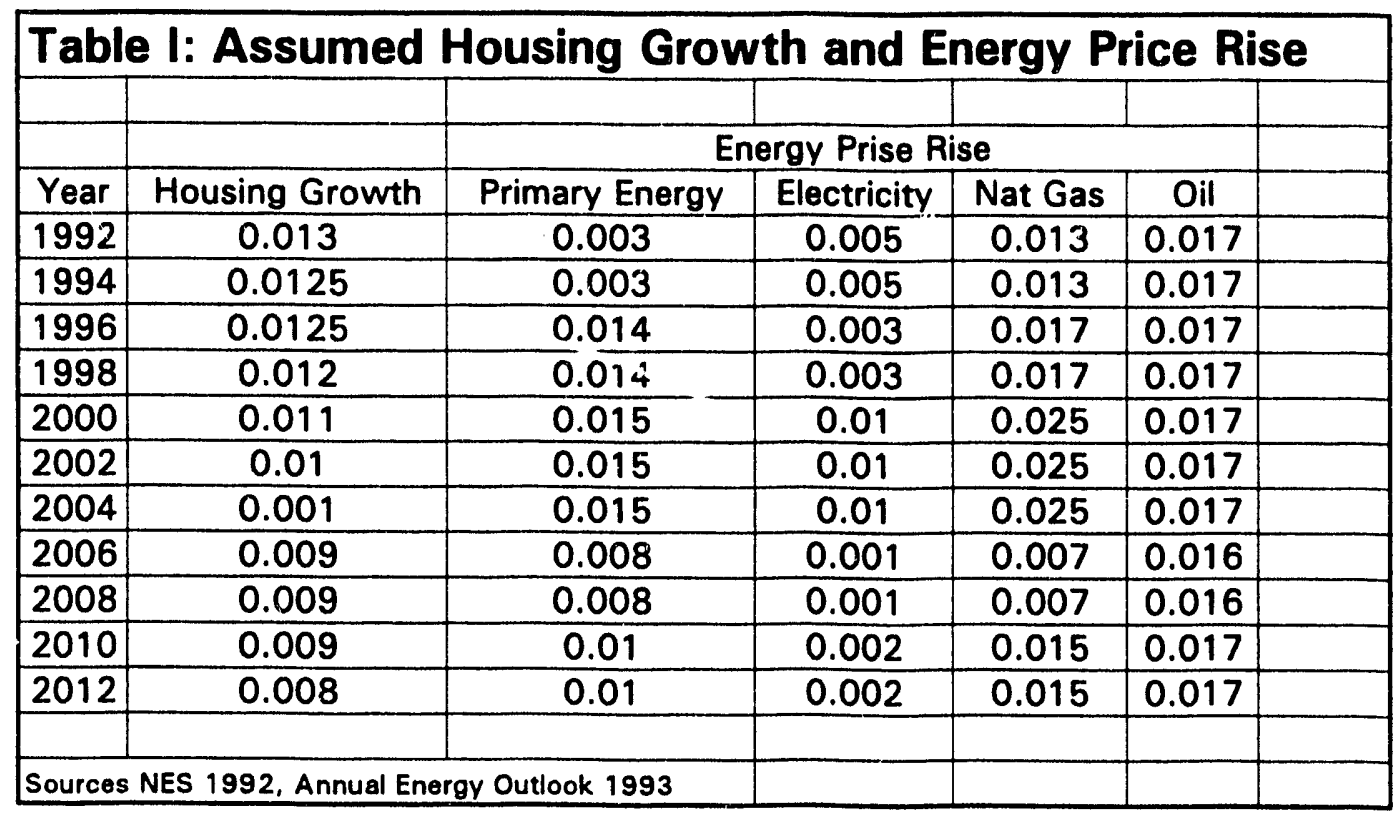




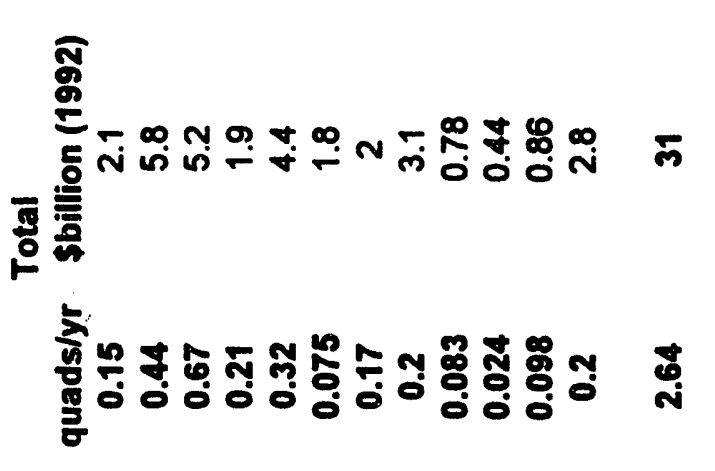

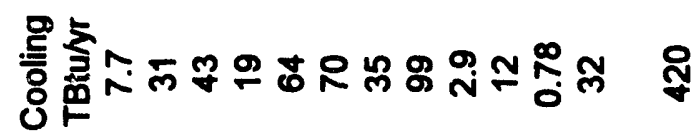

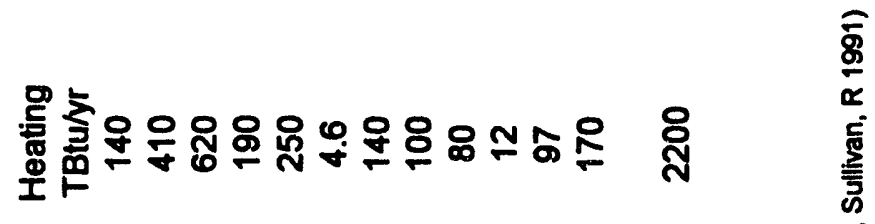

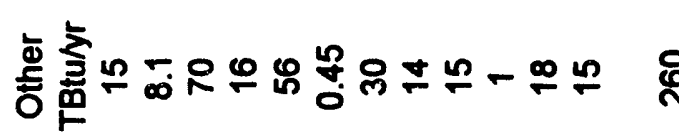

8

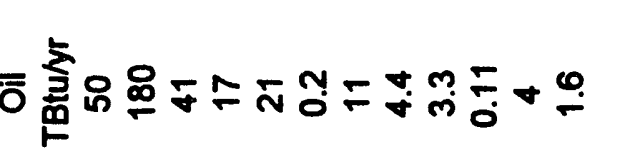

$\frac{d}{8}$

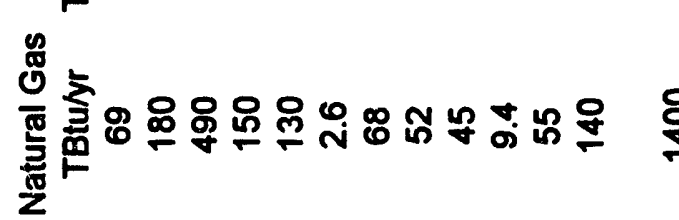

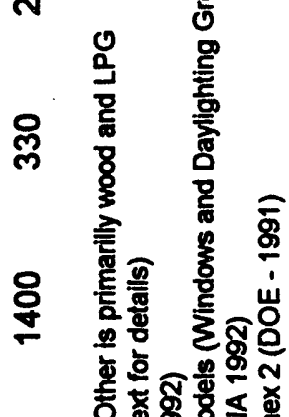

䒺文

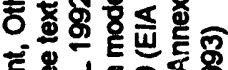

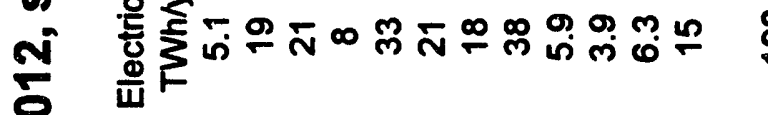

옹

응

兽

흥

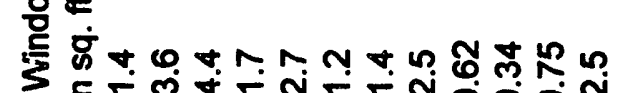

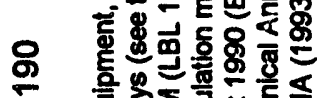

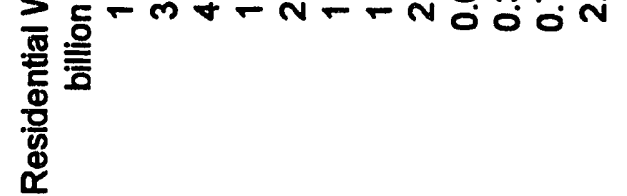

ก

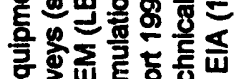

它罂

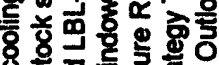

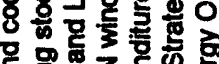

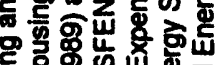

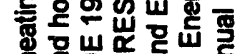

ล

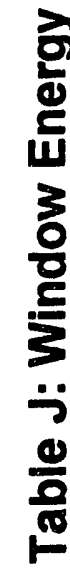

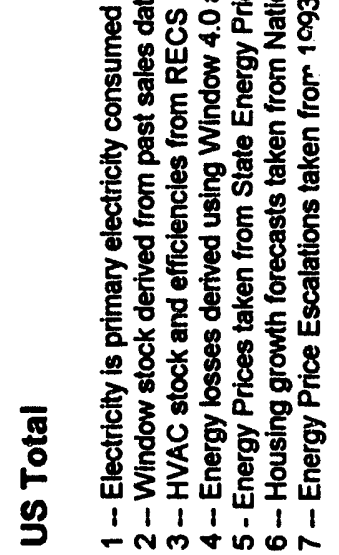




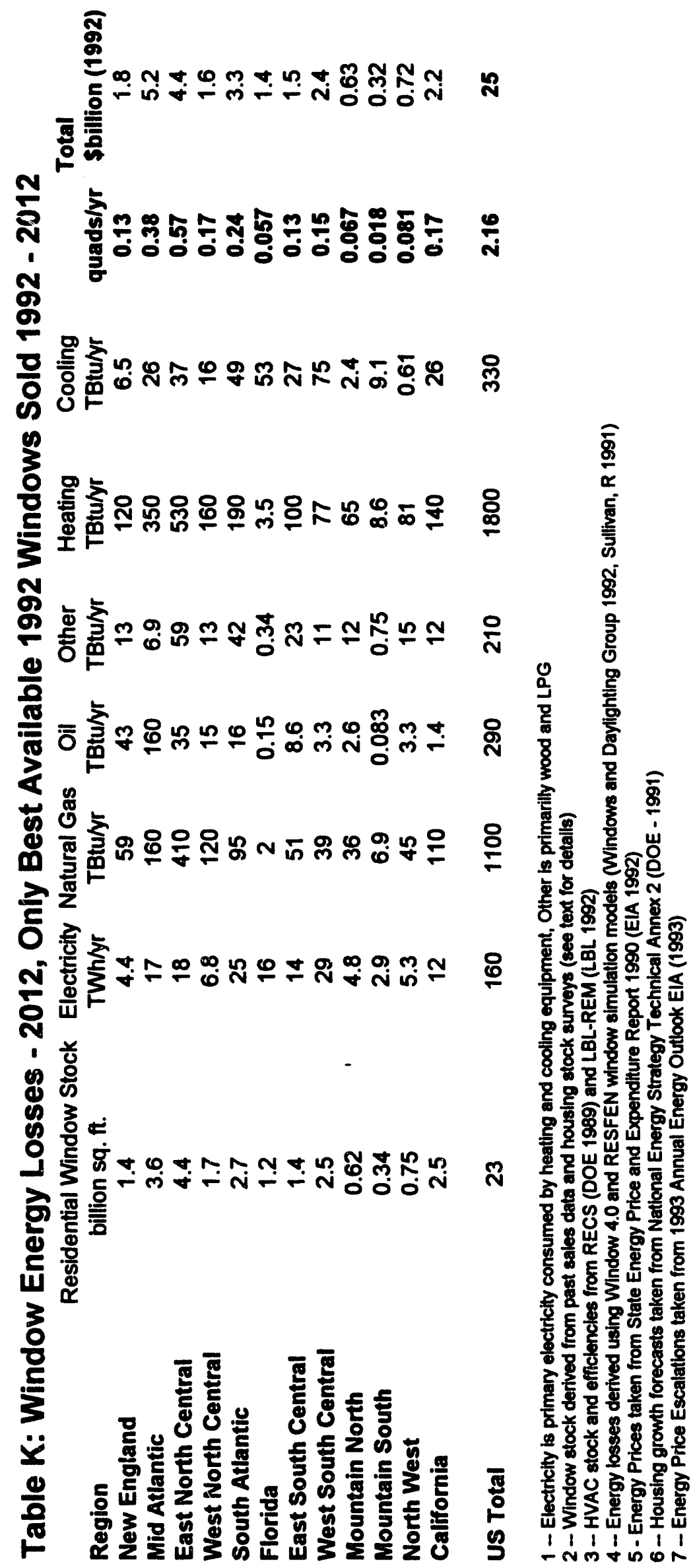




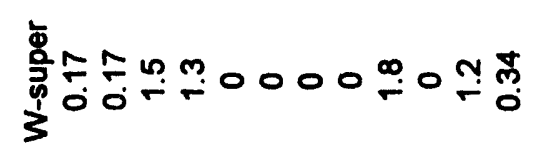

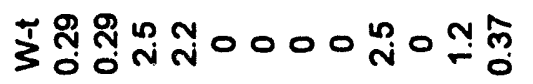

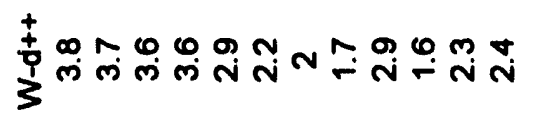

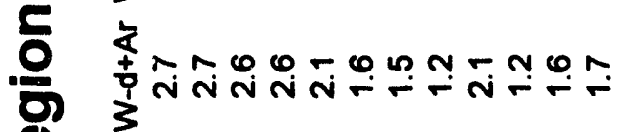

(d)

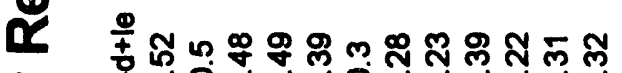

उ)

ํㅜㄴ

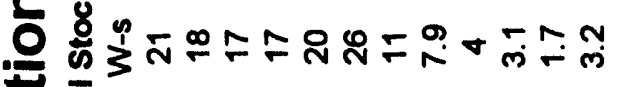

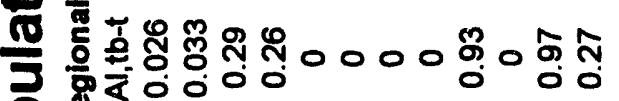

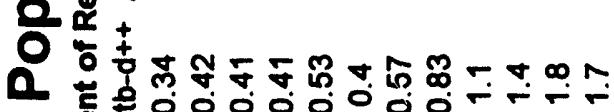

$\rightarrow$ 흉

ठิ :

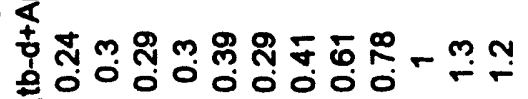
先

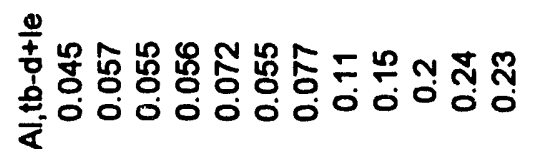
ํำ 0 N

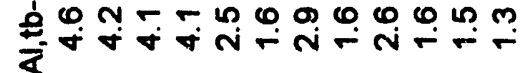

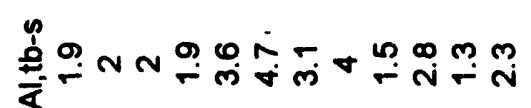

₹ द

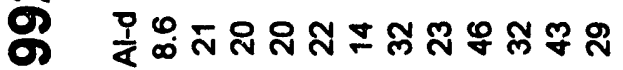
\%)

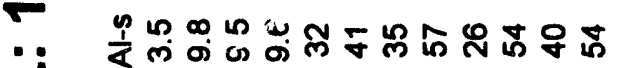
(1)

은

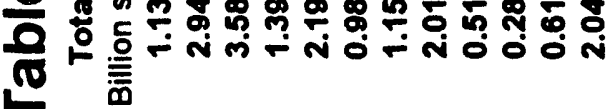
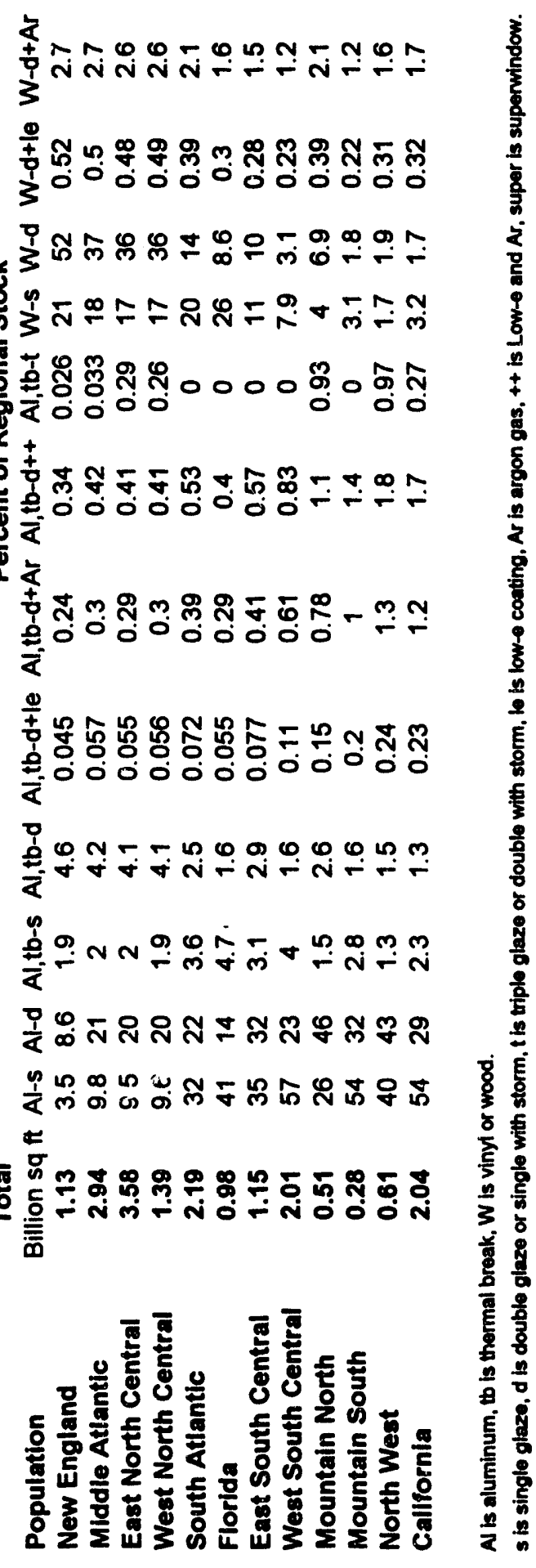

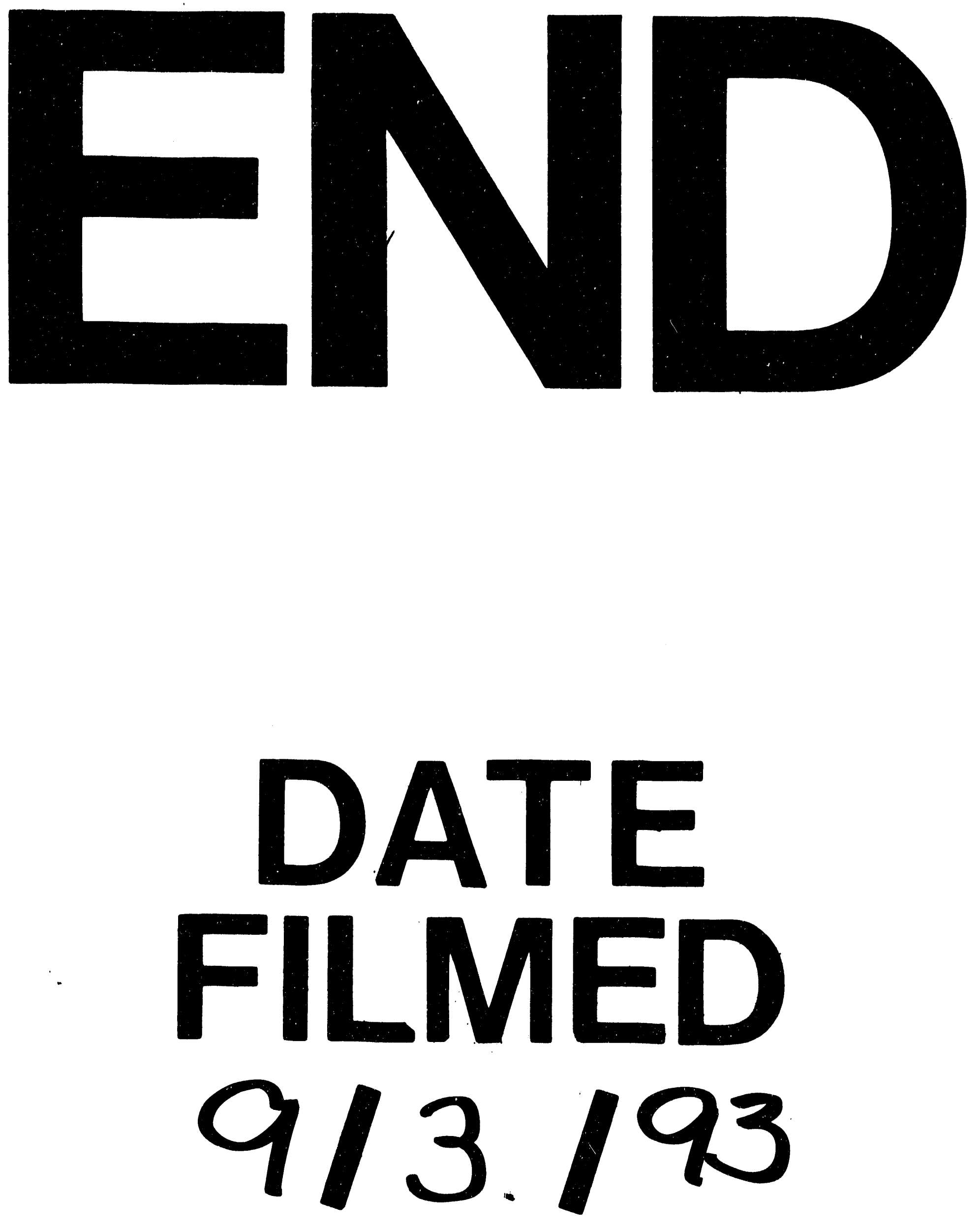
